\title{
Sensitivity of photolysis frequencies and key tropospheric oxidants in a global model to cloud vertical distributions and optical properties
}

Hongyu Liu ${ }^{1}$, James H. Crawford ${ }^{2}$, David B. Considine ${ }^{2}$, Steven Platnick ${ }^{3}$, Peter M. Norris ${ }^{3,4}$, Bryan N. Duncan ${ }^{3,4}$, Robert B. Pierce ${ }^{2,5}$, Gao Chen ${ }^{2}$, and Robert M. Yantosca ${ }^{6}$

${ }^{1}$ National Institute of Aerospace, Hampton, VA

${ }^{2}$ NASA Langley Research Center, Hampton, VA

${ }^{3}$ NASA Goddard Space Flight Center, Greenbelt, MD

${ }^{4}$ University of Maryland, Baltimore County, MD

${ }^{5}$ Now at NOAA/NESDIS/STAR, WI

${ }^{6}$ Harvard University, Cambridge, MA

Short Title: Radiative Effects of Clouds: Sensitivity

Keywords: photolysis rate, tropospheric ozone, hydroxyl radical, solar radiation, cloud optical depth, cloud absorption, cloud overlap, 3-D global CTM

Manuscript submitted to Journal of Geophysical Research-Atmospheres; revised, Feb. 18, 2009

Correspondence: Hongyu Liu Mail Stop 401B, NASA Langley Research Center Hampton, VA 23681

Tel: 757-864-3191; Fax: 757-864-6326

Email: hyl@,nianet.org 
Abstract. Clouds affect tropospheric photochemistry through modification of solar radiation that determines photolysis frequencies. As a follow-up study to our recent assessment of the radiative effects of clouds on tropospheric chemistry, this paper presents an analysis of the sensitivity of such effects to cloud vertical distributions and optical properties (cloud optical depths (CODs) and cloud single scattering albedo), in a global 3-D chemical transport model (GEOS-Chem). GEOS-Chem was driven with a series of meteorological archives (GEOS1STRAT, GEOS-3 and GEOS-4) generated by the NASA Goddard Earth Observing System data assimilation system. Clouds in GEOS1-STRAT and GEOS-3 have more similar vertical distributions (with substantially smaller CODs in GEOS1-STRAT) while those in GEOS-4 are optically much thinner in the tropical upper troposphere. We find that the radiative impact of clouds on global photolysis frequencies and hydroxyl radical $(\mathrm{OH})$ is more sensitive to the vertical distribution of clouds than to the magnitude of column CODs. With random vertical overlap for clouds, the model calculated changes in global mean $\mathrm{OH}\left(\mathrm{J}\left(\mathrm{O}^{1} \mathrm{D}\right), \mathrm{J}\left(\mathrm{NO}_{2}\right)\right)$ due to the radiative effects of clouds in June are about $0.0 \%(0.4 \%, 0.9 \%), 0.8 \%(1.7 \%, 3.1 \%)$, and $7.3 \%$ $(4.1 \%, 6.0 \%)$, for GEOS1-STRAT, GEOS-3 and GEOS-4, respectively; the geographic distributions of these quantities show much larger changes, with maximum decrease in $\mathrm{OH}$ concentrations of $\sim 15-35 \%$ near the midlatitude surface. The much larger global impact of clouds in GEOS-4 reflects the fact that more solar radiation is able to penetrate through the optically thin upper-tropospheric clouds, increasing backscattering from low-level clouds. Model simulations with each of the three cloud distributions all show that the change in the global burden of ozone due to clouds is less than 5\%. Model perturbation experiments with GEOS-3, where the magnitude of 3-D CODs are progressively varied from $-100 \%$ to $100 \%$, predict only modest changes $(<5 \%)$ in global mean $\mathrm{OH}$ concentrations. $\mathrm{J}\left(\mathrm{O}^{1} \mathrm{D}\right), \mathrm{J}\left(\mathrm{NO}_{2}\right)$ and $\mathrm{OH}$ 
concentrations show the strongest sensitivity for small CODs and become insensitive at large CODs due to saturation effects. Caution should be exercised not to use in photochemical models a value for cloud single scattering albedo lower than about 0.999 in order to be consistent with the current knowledge of cloud absorption at the ultraviolet wavelengths.

\section{Introduction}

Tropospheric ozone $\left(\mathrm{O}_{3}\right)$ is an important greenhouse gas, and hydroxyl radical $(\mathrm{OH})$ determines the oxidative capacity of the troposphere [Thompson, 1992]. Any perturbations to $\mathrm{O}_{3}$ and $\mathrm{OH}$ have important implications for climate change [IPCC, 2001]. Clouds affect tropospheric photochemistry through modification of solar radiation that determines photolysis frequencies [Thompson et al., 1984; Crawford et al., 1999], in addition to their roles in tropospheric chemistry via the processes of heterogeneous chemistry, wet removal, convective transport of trace gases and aerosols and nitrogen oxides $\left(\mathrm{NO}_{\mathrm{x}}\right)$ emissions due to lightning associated with deep convective clouds. However, there have been few studies of the impact of clouds on photolysis frequencies and tropospheric oxidants such as $\mathrm{O}_{3}$ and $\mathrm{OH}$ on a global scale [Krol and van Weele, 1997; Tie et al., 2003; Liu et al., 2006]. Cloud amounts and distributions may very well change in a changing climate and better understanding of the global impact of clouds is essential for predicting the feedback of climate change on tropospheric chemistry. We recently assessed the radiative effects of clouds on photolysis frequencies and key oxidants in the troposphere with GEOS-Chem [Liu et al., 2006], a global three-dimensional (3-D) chemical transport model (CTM) driven by assimilated meteorological observations. In this paper, we apply the same model to examine the sensitivity of this effect to the uncertainty associated with the distributions and optical properties of clouds. 
Modeling studies of the radiative effects of clouds on tropospheric chemistry have emphasized the need to account for the spatial and temporal variability of photolysis frequencies under different atmospheric (including cloud) conditions [Wild et al., 2000; Mao et al., 2003; Tang et al., 2003; Tie et al., 2003; Yang and Levy, 2004; Liu et al., 2006]. Results indicated that photolysis frequencies are enhanced above and in the upper portion of cloud layers and are reduced below optically thick clouds, consistent with observations [Lefer et al., 2003]. Including in the model the effect of vertical subgrid variability of cloudiness (cloud overlap) on radiative transfer has a significant impact on above-cloud (below-cloud) enhancements (reductions) [Feng et al., 2004; Liu et al., 2006]. Nevertheless, we found that regardless of the different assumptions about cloud overlap, the global average effect remained modest in GEOS-Chem when the model was driven by the GEOS-3 assimilated meteorology, reflecting an offsetting effect above and below clouds [Liu et al., 2006]. This was consistent with the finding of Krol and Weele [1997] who found that the effect of clouds on the globally averaged lifetime of methane $\left(\mathrm{CH}_{4}\right)$ was small due to compensating effects above and below clouds.

Previous estimates of the radiative impact of clouds on global tropospheric chemistry were based on CTMs driven by different meteorology that contained different cloud fields, either from general circulation models (GCMs) [e.g., Tie et al., 2003; Wu et al., 2007] or from data assimilation systems [e.g., Liu et al., 2006; Wu et al., 2007]. The representation of clouds in current climate models is still a challenging task because cloud processes typically take place on scales that are not adequately resolved by these models and have to be parameterized [Quante, 2004; Stephens, 2005]. Recently, Zhang et al. [2005] compared clouds in ten GCMs and found that the majority of the models overestimated optically thick clouds by over a factor of 2 , while underestimating optically intermediate and optically thin clouds. The uncertainty in simulated 
clouds (and relevant radiative processes) has been recognized as a large limiting factor in current assessments of climate change [IPCC, 2001, 2007].

As a follow-up study to our recent assessment of the radiative effects of clouds on tropospheric chemistry [Liu et al., 2006], this paper presents an analysis of the sensitivity of this effect to cloud vertical distributions and optical properties with the use of GEOS-Chem [Bey et al., 2001; Park et al., 2004] coupled with the Fast-J radiative transfer model [Wild et al., 2000]. We drive GEOS-Chem with a series of meteorological archives from the Goddard Earth Observing System data assimilation system (GEOS DAS) at the NASA Global Modeling and Assimilation Office (GMAO), which are characterized by distinctly different cloud fields, in particular cloud vertical distributions and CODs. We will show that the radiative impact of clouds on global tropospheric chemistry is more sensitive to the vertical distribution of clouds than to the magnitude of CODs, and is also sensitive to the assumption about cloud absorption. We will also show that differing optical depths and vertical distributions of clouds cannot explain the contrasting sensitivities of tropospheric photochemistry to clouds in the two modeling studies of Tie et al. [2003] and Liu et al. [2006].

The paper is organized as follows. Section 2 gives a brief description of the GEOS-Chem model and its evaluation with observations. Section 3 presents the cloud fields in three GEOS meteorological archives and their evaluations with satellite observations. The sensitivities of photolysis frequencies and key oxidants to cloud vertical distributions, CODs, and cloud absorption of solar radiation are examined in sections 4 through 7 , followed by summary and conclusions in section 8 .

\section{Model Description}


GEOS-Chem is a global 3-D model of tropospheric $\mathrm{O}_{3}-\mathrm{NO}_{\mathrm{x}}$-hydrocarbon chemistry coupled to aerosol chemistry, driven by assimilated meteorological observations with 3- to 6hour resolution from the Goddard Earth Observing System (GEOS) of the NASA Global Modeling and Assimilation Office (GMAO). It solves the chemical evolution of $\sim 90$ species and transports 41 chemical tracers. The initial description of the model as applied to simulation of tropospheric $\mathrm{O}_{3}-\mathrm{NO}_{\mathrm{x}}$-hydrocarbon chemistry was presented by Bey et al. [2001], with significant updates by Martin et al. [2002], Park et al. [2004] and Evans and Jacob [2005]. In particular, Park et al. [2004] coupled aerosol (including sulfate-nitrate-ammonium, carbonaceous aerosols, sea salt, and mineral dust) chemistry with $\mathrm{O}_{3}-\mathrm{NO}_{\mathrm{x}}$-hydrocarbon chemistry. The model simulation of global tropospheric chemistry using different generations of GEOS assimilated meteorology has been evaluated in a number of studies since it was first evaluated by Bey et al. [2001]. The reader is referred to Liu et al. [2006] for a brief review. In this study we use GEOS-Chem version 7.1 (see http://www.as.harvard.edu/ctm/geos/) [Heald et al., 2006; Martin et al., 2006]. Global simulations of tropospheric chemistry were conducted for the years of 1996 and 2001. The simulation years were chosen so as to use different meteorological archives that have different cloud fields. All simulations in this study were conducted with five-month initialization and we analyze the model results for the years of 1996 and 2001.

Three generations of GEOS meteorological products are used for the simulation years as follows: GEOS1-STRAT for 1996 (2 latitude $\times 2.5^{\circ}$ longitude horizontal resolution, 46 vertical levels, top at $0.1 \mathrm{hPa})$, GEOS-3 ( $1^{\circ}$ latitude $\times 1^{\circ}$ longitude, 48 levels, top at $\left.0.01 \mathrm{hPa}\right)$ and GEOS4 both for 2001 ( $1^{\circ}$ latitude $\times 1.25^{\circ}$ longitude, 55 levels, top at $0.01 \mathrm{hPa}$, Bloom et al. [2005]). We have not included the latest GEOS-5 meteorological product because our main focus is on the sensitivity of tropospheric chemistry to different aspects (column integral and vertical 
116 distribution) of the COD. The three archives used (GEOS1-STRAT, GEOS-3 and GEOS-4)

117 provide continuity with our previous paper [Liu et al., 2006] and provide enough variability in

118 the COD distributions for the current sensitivity study. For computational expediency, we

119 degrade the horizontal resolution to $4^{\circ} \times 5^{\circ}$ and merge the $23(26,36)$ vertical levels above $50(85$,

$12080) \mathrm{hPa}$ for GEOS1-STRAT (GEOS-3, GEOS-4), retaining a total of $26(30,30)$ vertical levels.

121 The vertical levels for GEOS1-STRAT and GEOS-3 are defined along a sigma coordinate.

122 GEOS-4 employs a hybrid sigma-pressure coordinate system; the lowest 14 levels are pure

123 sigma levels and the rest (mainly above 200hPa) fixed pressure levels. The midpoints of the

124 lowest four levels in the GEOS1-STRAT (GEOS-4) data are at 50 (60), 250 (250), 600 (610),

125 and $1100(1200) \mathrm{m}$ above the surface for a column based at sea level. The GEOS-3 data have

126 finer resolution of the boundary layer with layer midpoints at 10, 50, 100, 200, 350, 600, 850,

127 and $1250 \mathrm{~m}$ above the surface. The cross-tropopause flux of $\mathrm{O}_{3}$ is specified with the Synoz

128 (synthetic $\mathrm{O}_{3}$ ) scheme [McLinden et al., 2000] by imposing a global net cross-tropopause flux of

$129475 \mathrm{Tg} \mathrm{O}_{3}$ per year (GEOS1-STRAT), $500 \mathrm{Tg} \mathrm{O}_{3}$ per year (GEOS-3), and $495 \mathrm{Tg} \mathrm{O}_{3}$ per year

130 (GEOS-4); the variability partly reflects the difference in circulations between meteorological

131 archives. A uniform global $\mathrm{CH}_{4}$ concentration of $1700 \mathrm{ppbv}$ is imposed.

Photolysis frequencies are calculated with the Fast-J radiative transfer algorithm of Wild

133 et al. [2000], which uses a seven-wavelength quadrature scheme and accounts accurately for

134 Rayleigh scattering as well as Mie scattering by aerosols and clouds. A total of 52 photolysis

135 reactions are included and photolysis calculations are performed every hour. Vertically resolved

136 CODs and cloud fractions are taken from the GEOS meteorological archives with 6-hour

137 resolution. To take into account the vertical subgrid variability of clouds (cloud overlap), we use 
138 in this paper the Approximate Random Overlap (RAN) scheme unless explicitly stated. The

139 RAN scheme assumes that the grid average COD is

$$
\tau_{\mathrm{c}^{\prime}}=\tau_{\mathrm{c}} \cdot f^{3 / 2}
$$

141 where $\tau_{\mathrm{c}}$ is the COD in the cloudy portion of the grid and $f$ is the cloud fraction in each layer 142 [Briegleb, 1992]. The column COD is the sum of $\tau_{\mathrm{c}^{\prime}}$ for each layer of the column. Briegleb 143 [1992] showed that RAN yields a reasonable approximation to a detailed random overlap 144 calculation for the heating rate. RAN is also a good approximation of the maximum-random 145 overlap, which is more computationally expensive, in terms of the radiative impact of clouds on tropospheric chemistry [Liu et al., 2006]. Because the linear scheme $(\mathrm{LIN})$, where $\tau_{\mathrm{c}}{ }^{\prime}=\tau_{\mathrm{c}} \cdot f$, was used for standard tropospheric chemistry simulations in all previous papers using GEOS-Chem, we also present model results with LIN when quantifying the global mean radiative effects of clouds (Table 1) for comparison purposes. Clouds are assumed to be fully scattering (i.e., cloud single scattering albedo SSA=1.0). Monthly mean surface albedos are those of Herman and Celarier (1997). The model uses climatological $\mathrm{O}_{3}$ concentrations as a function of latitude, altitude, and month to calculate the absorption of UV radiation by $\mathrm{O}_{3}$. Using tropospheric $\mathrm{O}_{3}$ concentrations from the model simulation (vs. climatology) has little effect on our results [Liu et al., 2006].

The radiative effects of clouds in the model are represented by subtraction of a clear-sky simulation from a cloudy-sky simulation. In the clear-sky simulation CODs are set to zero in the calculation of photolysis frequencies while other roles of clouds (i.e., transport, wet removal, heterogeneous chemistry and lightning $\mathrm{NO}_{\mathrm{x}}$ emissions associated with deep convective clouds) are present in both the clear-sky and cloudy-sky simulations.

\section{Cloud Fields}


In this section, we describe briefly how clouds are formed, intercompare CODs in the three GEOS meteorological archives, and evaluate the model diagnosed CODs with global satellite observations. Since Fast-J requires as input the grid-scale COD in vertical model layers, the intercomparison and evaluation will help us understand the sensitivities of tropospheric chemistry to these cloud fields.

\subsection{Cloud Formation}

In GEOS1-STRAT, convective and large-scale cloudiness are diagnosed as part of the cumulus and large-scale parameterizations [Takacs et al., 1994]. They are combined into random overlap (CLRO) and maximum overlap (CLMO) cloudiness. The total cloud fraction, $f$, at each level is then obtained by: $f=1$ - (1-CLRO) - (1-CLMO). CODs are specified based on cloud type and temperature. The "maximum overlap" clouds are assigned an optical depth of 16 per $100 \mathrm{mb}$ and the "random overlap" clouds are assigned an optical depth based on an empirical relation between local temperature and optical depth.

In GEOS-3, the occurrence of clouds is empirically diagnosed based on grid-scale relative humidity and subgrid-scale convection. For large-scale clouds, COD is empirically assigned values proportional to the diagnosed large-scale liquid water. For convective clouds, COD is prescribed as 16 per $100 \mathrm{mb}$. A temperature-dependence is used to distinguish between water and ice clouds. The total optical depth in a given model layer is computed as a weighted average between the large-scale and subgrid scale optical depths, normalized by the total cloud fraction in the layer.

In GEOS-4 and its parent general circulation model fvGCM (finite-volume GCM), the physics was adopted from the NCAR CCM3 (Community Climate Model version 3) and WACCM (Whole Atmosphere Community Climate Model) with several modifications [Kiehl et 
$184 a l ., 1998]$. The cloud microphysics follows the simple diagnostic condensate parameterization in

185 the standard CCM3. The diagnosis of cloud fraction uses a modified Slingo [1987] scheme.

186 Cloud fraction depends on relative humidity, vertical velocity, atmospheric stability and

187 convective mass fluxes. The scheme diagnoses three types of cloud, i.e., low-level marine

188 stratus, convective cloud, and layered cloud. The parameterization of cloud optical properties is

189 described in Kiehl et al. [1998].

190

191

192

193

194

195

196

197

198

199

200

201

202

203

204

205

206

\subsection{Evaluation of GEOS Cloud Optical Depths with Satellite Observations}

Since information about the global climatology of the vertical distribution of cloud water/ice content and optical depth is currently lacking, we focus on column CODs when evaluating model cloud fields against the observations. Satellite retrieved products of column CODs are available from the Moderate Resolution Imaging Spectroradiometer (MODIS) [Platnick et al., 2003] and the International Satellite Cloud Climatology Project (ISCCP) [Rossow et al., 1996; Rossow and Schiffer, 1999]. The standard ISCCP D2 data set [Rossow et al., 1996] reports as column CODs the averaged values of individual pixels with nonlinear weights that preserve the average cloud albedo (the so-called "radiative mean CODs" [Rossow et al., 2002]), while storing linear averages of individual pixel values of optical depth (the so-called "linear mean CODs" [Rossow et al., 2002]) in the form of mean cloud water content. It is important to note that ISCCP radiative mean CODs are about a factor of 2-3 smaller than the linear mean CODs (W.B. Rossow, personal communication, 2004). The MODIS data set provides linear mean CODs and geometric mean CODs, the latter being a proxy for radiative mean CODs [e.g., Oreopoulos and Cahalan, 2005].

We previously compared in Liu et al. [2006] GEOS-3 monthly (linear mean) CODs with MODIS (MOD08_M3.004) and ISCCP (D2, linear mean) retrievals for the year of 2001. We 
made a similar comparison between GEOS1-STRAT, GEOS-3, GEOS-4, MODIS (MOD08_M3.005) and ISCCP (D2) datasets for June (not shown). Both MODIS and ISCCP CODs show peaks in the tropics and at mid-latitudes in the Northern Hemisphere (NH) and the marine stratus region in the Southern Hemisphere $\left(\mathrm{SH}, \sim 50-60^{\circ} \mathrm{S}\right)$. GEOS CODs show similar features, with GEOS1-STRAT and GEOS-4 CODs substantially lower than the satellite retrievals by factors of about 5 and 2, respectively. The GEOS CODs we used are diurnal averages, but they are almost identical (in a zonal mean sense) to the daytime averages. Although GEOS-3 CODs are closest to the satellite retrievals, GEOS-3 tends to overestimate CODs in the tropics and $\mathrm{NH}$ lower mid-latitudes (extending from the subtropics). MODIS and ISCCP retrievals show high CODs at high southern latitudes, presumably due to errors associated with COD retrievals over snow or ice cover. ISCCP seems to have a similar problem in the summer $(\mathrm{NH})$ very high latitudes, though MODIS appears to do much better in this latter case. This comparison, however, did not take into account how clouds overlap in the vertical.

We improve the comparison between GEOS and satellite CODs by considering cloud overlap. MODIS and ISCCP observations of global cloudiness assume only a single cloud layer is present in a given pixel and therefore implicitly include the effects of cloud overlap. Since we use in this study the RAN cloud overlap scheme in our model standard simulation, we compare the GEOS effective column CODs under the RAN scheme with MODIS and ISCCP all-sky grid-box (radiative mean) CODs (Figure 1a). GEOS CODs are $\tau_{\mathrm{c}}$ ' values in equation (1) integrated in the vertical column. MODIS and ISCCP all-sky grid-box CODs are averages over both grid-box cloudy and clear areas with nonlinear weights that preserve the average cloud albedo, as derived in the Appendix. 
MODIS radiative mean CODs are very close to those of ISCCP in the tropics while the former is somewhat larger at mid-latitudes. As with linear mean CODs (not shown), MODIS and ISCCP radiative mean CODs also show peaks in the tropics and mid-latitudes (Figure 1a). 232 Relative to linear mean CODs, GEOS effective CODs under the RAN scheme (Figure 1a) have smaller magnitude with similar latitudinal variations. These CODs also differ substantially 234 among the GEOS archives. In the tropics, GEOS-4 effective CODs are most close to MODIS and ISCCP radiative mean CODs; at mid-latitudes, GEOS-4 and GEOS-3 effective CODs appear to bracket MODIS and ISCCP radiative mean CODs.

Figure 1b shows the relevant zonal mean total cloud fractions. The MODIS MOD35 cloud-mask fraction (i.e., "Cloud_Fraction_Mean_Mean” in the Collection 5 processing stream) is very close to the ISCCP cloud fraction. Both are diurnal-mean cloud fractions. Note that the MOD35 daytime-mean cloud-mask fraction (not shown) is very close to the corresponding 241 diurnal-mean fraction. This indicates that there is not a large diurnal variation, at least in the zonal means, and justifies the combination of diurnal-mean ISCCP cloud fractions and the daytime-mean ISCCP CODs in the ISCCP all-sky calculations for Figures 1a and 1b. Relative to total cloud fractions in GEOS1-STRAT and GEOS-4, those in GEOS-3 appear to better agree with ISCCP retrievals as well as total cloud fractions from the MOD35 cloud mask. A similar under-prediction of GEOS-4 zonal mean cloud fraction was reported by Norris and da Silva [2007] for January 2001.

Also shown in Figure 1b (thick solid line) is the MOD06 COD-retrieval cloud fraction ("Cloud_Fraction_Combined_FMean"). This is the fraction of MODIS pixels classified as cloudy for the purposes of doing COD retrievals. This is the appropriate cloud fraction to use for MODIS all-sky COD calculations and the one used in Figures 1a. It is significantly smaller than 
252 the cloud-mask fraction, because the MODIS COD retrieval algorithms are more selective than

253 the cloud mask in order to return accurate COD values. This increased selectivity tends to 254 remove dubiously cloudy pixels that tend to have very small COD values anyway, so does not 255 produce an underestimate of all-sky COD. This was verified against Collection 004 retrievals 256 (not shown), which were less selective, with higher cloud fractions, but produced all-sky CODs 257 similar to Collection 005 values.

Discrepancies between CODs in the three GEOS archives include not only their magnitudes but vertical distributions. We intercompare in Figure 2 the latitude-height cross sections of monthly zonal mean effective cloud extinction coefficients $\left(\mathrm{km}^{-1}\right)$ and cloud fractions in GEOS1-STRAT (1996), GEOS-3 (2001) and GEOS-4 (2001) for June. Clouds in GEOS-4 are optically much thinner in the tropical upper troposphere compared to those in GEOS1-STRAT and GEOS-3; the latter two cases exhibit more similar spatial (especially vertical) distributions.

The global distributions of GEOS1-STRAT, GEOS-3, and GEOS-4 monthly mean column effective CODs are shown in Figure 3 in comparison with MODIS and ISCCP all-sky grid-box radiative mean CODs for March 2001 when frequent cyclogenesis occurred in the NH. Note the smaller color scale for GEOS1-STRAT. Also shown in Figure $\mathbf{3}$ are the probability distribution functions (PDF) of global monthly mean column CODs in each dataset. CODs in all GEOS archives show maxima in the tropics associated with deep convective clouds and at midlatitudes associated with extratropical cyclones in the $\mathrm{NH}$ and marine stratiform clouds in the SH. Despite the different magnitudes of column CODs among the three archives, their features in the global distributions (i.e., maxima in the tropics and at midlatitudes) are consistent with those in the MODIS and ISCCP cloud retrieval products. Their probability distribution functions 
274 indicate that CODs in the range of 1-3 are mostly seen in all GEOS archives (except GEOS1-

275 STRAT) as well as MODIS and ISCCP retrievals.

\section{Sensitivity of Photolysis Frequencies to Cloud Optical Depths}

In this section, we examine the sensitivity of the global impact of GEOS1-STRAT,

GEOS-3, and GEOS-4 clouds on photolysis frequencies. We focus on $\mathrm{J}\left(\mathrm{O}^{1} \mathrm{D}\right)$ and $\mathrm{J}\left(\mathrm{NO}_{2}\right)$, which are the most critical parameters for determining $\mathrm{OH}$ and $\mathrm{O}_{3}$ concentrations [Thompson and Stewart, 1991].

Figure 4 shows the simulated percentage changes in the June monthly daily mean $\mathrm{J}\left(\mathrm{O}^{1} \mathrm{D}\right)$ due to the radiative effects of clouds with GEOS1-STRAT, GEOS-3, and GEOS-4, respectively. With GEOS1-STRAT and GEOS-3, $\mathrm{J}\left(\mathrm{O}^{1} \mathrm{D}\right)$ in the tropics is enhanced by up to $\sim 10-15 \%$ above the high clouds, and reduced by up to $\sim 5-10 \%$ (GEOS1-STRAT) and $\sim 10-20 \%$ (GEOS-3) below. These enhancements (reductions) reflect the backscattering (attenuation) of solar UV radiation above (below) the deep convective clouds. Similar effects are also seen above and below the low-level clouds at NH and SH midlatitudes. Overall, GEOS1-STRAT and GEOS-3 yield similar patterns in terms of the regions of $\mathrm{J}\left(\mathrm{O}^{1} \mathrm{D}\right)$ enhancements and reductions due to the radiative impact of clouds, reflecting their similar vertical distributions of clouds (Figure 2). However, relative to GEOS1-STRAT, GEOS-3 gives larger enhancements (reductions) above (below) the clouds because of larger CODs.

By contrast, with GEOS-4, $\mathrm{J}\left(\mathrm{O}^{1} \mathrm{D}\right)$ is enhanced (by $\sim 5-10 \%$ ) in most of the tropical troposphere and is reduced (by $\sim 5 \%$ ) only near the surface $(<\sim 1 \mathrm{~km})$. The optically much thinner clouds in the tropical upper troposphere in GEOS-4 allow more solar UV radiation to penetrate through and be subsequently reflected by low-level thick clouds. The net changes in $J\left(O^{1} \mathrm{D}\right)$ in 
297 the tropical middle troposphere are determined by the competition between the radiative effects

298 of high and low clouds. Indeed, the optically thicker clouds in the tropical upper troposphere in 299 GEOS1-STRAT and GEOS-3 allow less solar UV radiation to penetrate down, resulting in net 300 reductions in the middle troposphere.

301 The sensitivity of $\mathrm{J}\left(\mathrm{NO}_{2}\right)$ to the three cloud fields is spatially similar to that of $\mathrm{J}\left(\mathrm{O}^{1} \mathrm{D}\right)$ but 302 has a larger magnitude (not shown); the latter was discussed in Liu et al. [2006].

\section{Sensitivity of Key Oxidants to Cloud Optical Depths}

We examine in this section the sensitivity of $\mathrm{OH}$ and $\mathrm{O}_{3}$ calculations to the CODs in the and monthly zonal means (section 5.2).

\subsection{Global Mean}

Shown in Table 1 are the simulated percentage changes in the global mean concentrations of key oxidants in the troposphere, photolysis frequencies and global mean lifetimes of methylchloroform $\left(\mathrm{CH}_{3} \mathrm{CCl}_{3}, \mathrm{MCF}\right)$ and $\mathrm{CH}_{4}$ due to the radiative effects of clouds with the GEOS1-STRAT (1996), GEOS-3 (2001), and GEOS-4 (2001) meteorological archives for June used in previous standard versions of the GEOS-Chem model and the corresponding results are presented here for comparison. With GEOS1-STRAT, calculated global mean changes in OH, $\mathrm{O}_{3}, \mathrm{NO}_{\mathrm{x}}, \mathrm{HO}_{2}, \mathrm{CH}_{2} \mathrm{O}, \mathrm{CO}, \mathrm{J}\left(\mathrm{O}^{1} \mathrm{D}\right), \mathrm{J}\left(\mathrm{NO}_{2}\right)$, and $\mathrm{J}\left(\mathrm{CH}_{2} \mathrm{O}\right)$ for June are generally less than a few percent, using either RAN or LIN. We found the same (i.e., less than $\sim 6 \%$ ) previously with GEOS-3 [Liu et al., 2006]. The slight differences between the model results for GEOS-3 reported in Table 1 here and Table 2 of Liu et al. [2006] reflect an updated version of the model 
used in this study. In January, both GEOS1-STRAT and GEOS-3 yield global mean changes that are still less than $\sim 6 \%$ (RAN) or $\sim 9 \%$ (LIN). As we discussed in section 4 and will discuss further below, the global mean effects are similar for these two meteorological archives because of their similar vertical distribution of clouds, even though their column CODs differ by a factor of about 5. The fact that the global mean effect remains modest when driven with GEOS1STRAT or GEOS-3 reflects mainly an offsetting effect of above-cloud enhancements and belowcloud reductions.

GEOS-4 cloud perturbations to global mean $\mathrm{OH}$ concentrations and photolysis frequencies are much larger than occurs with either GEOS1-STRAT or GEOS-3, in particular when LIN is used for cloud overlap. For instance, global mean $\mathrm{OH}$ concentrations change by $\sim 7 \%$ (RAN) or $\sim 13 \%$ (LIN) due to the effects of clouds in GEOS-4 (versus $<\sim 2 \%$ change in GEOS1-STRAT and GEOS-3). This is surprising given that the column CODs in GEOS-4 are larger (smaller) than those in GEOS1-STRAT (GEOS-3) by a factor of $\sim 2.5$ (2). The larger global mean effect in our model with GEOS-4 results from the fact that optically thin upper-tropospheric clouds allow the (optically thick) lower-tropospheric clouds to have a large radiative effect. In other words, solar radiation can penetrate through the upper troposphere and is reflected by low-level thick clouds, increasing photochemical activity in most of the troposphere. Such large effects of clouds on $\mathrm{OH}$ were also seen in GEOS-Chem simulations driven by GISS GCM meteorological data, which has thick clouds in the tropical lower troposphere [Wu et al., 2007]. On the other hand, with GEOS-4, the differences in cloud perturbations to global mean $\mathrm{OH}$ concentrations and photolysis frequencies due to the RAN and LIN assumptions used in the model are much larger than those with GEOS1-STRAT and GEOS-3. It is because the optically much thinner (thicker) 
high clouds in GEOS-4 (GEOS1-STRAT and GEOS-3) enhance (reduce) the effect of different assumptions about cloud overlap on the reflection from low clouds.

We calculated the lifetimes of MCF and $\mathrm{CH}_{4}$, proxies for the global mean $\mathrm{OH}$ concentrations. With GEOS1-STRAT or GEOS-3, the annual mean lifetime of MCF $\left(\mathrm{CH}_{4}\right)$ increases by less than a few percent as a result of the radiative effects of clouds (Table 1). We find that the $\mathrm{MCF}\left(\mathrm{CH}_{4}\right)$ lifetime may increase even if global mean $\mathrm{OH}$ concentrations increase. This is because the MCF-OH $\left(\mathrm{CH}_{4}-\mathrm{OH}\right)$ reaction constant is temperature dependent and the MCF $\left(\mathrm{CH}_{4}\right)$ lifetime is more sensitive to the $\mathrm{OH}$ concentrations in the lower troposphere (versus the middle and upper troposphere) and the tropics (versus higher latitudes). With GEOS-4, annual mean lifetimes of $\mathrm{MCF}$ and $\mathrm{CH}_{4}$ decrease by $6 \%$ (RAN) or $11 \%$ (LIN) due to the effects of clouds. As we will show below, this large decrease compared to that with GEOS1-STRAT or GEOS-3 reflects the broader increases in $\mathrm{OH}$ concentrations in the free troposphere, including the tropics, in the model with GEOS-4. The very large changes in the effects on MCF and CH4 lifetimes due to the RAN and LIN assumptions (i.e., $-6 \%$ vs. $-11 \%$ ) are due to the large changes in the effects on $\mathrm{OH}$ concentrations, as discussed above. One may note that even without clouds, the MCF $(\mathrm{CH} 4)$ lifetime in the simulation with GEOS-4 is significantly longer than that with GEOS1-STRAT or GEOS-3. (hyl note: CH4 lifetime in GEOS-4 is $\sim 12$ years which is much higher than 9.8 years previously reported by Wu et al. [2007]. My OH in GEOS-4 is too low. I'm investigating this by re-running GEOS-4 simulations. GEOS-3 results agree with those of Wu et al.)

\subsection{Zonal Mean}

Figure 5 shows simulated percentage changes in monthly zonal mean $\mathrm{OH}$ and $\mathrm{O}_{3}$ due to the radiative effects of clouds for June when the model is driven by GEOS1-STRAT, GEOS-3 
and GEOS-4, respectively. As with photolysis frequencies (Figure 4), the regions of $\mathrm{OH}$ enhancements and reductions due to the radiative impact of clouds show similar patterns with GEOS1-STRAT and GEOS-3 because of similar vertical distributions of clouds in the two archives, although the magnitude of their respective relative changes in $\mathrm{OH}$ are different. In the tropics, $\mathrm{OH}$ is enhanced by up to $\sim 5 \%$ (GEOS1-STRAT) or $\sim 5-10 \%$ (GEOS-3) above the deep convective clouds, and reduced by $\sim 5-10 \%$ (GEOS1-STRAT) or $\sim 5-20 \%$ (GEOS-3) below, reflecting the backscattering (attenuation) of solar radiation above (below) the clouds. At $\mathrm{NH}$ midlatitudes, $\mathrm{OH}$ is enhanced by $\sim 2-5 \%$ (GEOS1-STRAT) or $\sim 5-10 \%$ (GEOS-3) above the lowlevel clouds; at $\mathrm{SH}$ subtropics, $\mathrm{OH}$ is enhanced by $\sim 5 \%$; at $\mathrm{SH}$ high latitudes, the impact of clouds on $\mathrm{OH}$ does not show consistent patterns. Near the surface, $\mathrm{OH}$ decreases by up to $\sim 15-$ $35 \%$ because of clouds, with the largest percentage decreases occurring at midlatitudes. By contrast, with GEOS-4, OH is enhanced (by $\sim 5-10 \%$ ) in most of the troposphere and is reduced (by up to $\sim 20 \%$ ) only near the surface $(<\sim 1 \mathrm{~km})$. Again, enhanced $\mathrm{OH}$ in the tropical middle troposphere is a result of the optically much thinner clouds in the tropical upper troposphere in GEOS-4, allowing solar UV radiation to not only penetrate down but be reflected back by lowlevel clouds.

With GEOS1-STRAT and GEOS-3, the maximum impact of clouds on $\mathrm{O}_{3}(\sim 2-5 \%)$ is seen in the tropical upper troposphere with a trivial impact elsewhere (Figure 5, right panels). The pattern of enhancements above clouds and reductions below clouds for $\mathrm{OH}$ are not seen for $\mathrm{O}_{3}$, partly reflecting the relatively long lifetime of $\mathrm{O}_{3}$ and the short lifetime of $\mathrm{OH}$. More importantly, the tropical lower troposphere is overall a regime of net $\mathrm{O}_{3} \operatorname{loss}(\sim 1 \mathrm{ppbv} / \mathrm{day}$ on zonal average) due to a low $\mathrm{NO}_{\mathrm{x}}$ environment; therefore, the radiative effects of tropical deep convective clouds suppress this net $\mathrm{O}_{3}$ loss (e.g., by a few percent with GEOS-3) primarily via 
388 the reaction $\mathrm{O}\left({ }^{1} \mathrm{D}\right)+\mathrm{H}_{2} \mathrm{O} \rightarrow 2 \mathrm{OH}$, increasing $\mathrm{O}_{3}$ in this part of the troposphere. On the other 389 hand, with GEOS-4, the overall impact of clouds on $\mathrm{O}_{3}$ is small, with a maximum in the 390 middle/upper troposphere at NH high latitudes. We showed in Liu et al. [2006] that tropical 391 upper tropospheric $\mathrm{O}_{3}$ is much less sensitive to the radiative effects of clouds in the GEOS-Chem 392 model (driven with GEOS-3) than previously reported by Tie et al. [2003] using the MOZART-2 393 model ( $\sim 5 \%$ versus $\sim 20-30 \%)$. Here we find that when driven with the other two meteorological 394 archives that feature either different magnitudes of column CODs or different vertical 395 distributions in the vertical, GEOS-Chem still shows much less sensitivity of tropospheric $\mathrm{O}_{3}$ to 396 the radiative effects of clouds than does MOZART-2. Indeed, our result was quite comparable to 397 that of Wild [2007] who found a global $\mathrm{O}_{3}$ burden change of $2.5 \%$ when all cloud cover was 398 removed in the FRSGC/UCI CTM. It appears, however, that global distributions of clouds in the 399 MOZART-2 model used by Tie et al. [2003] are similar to those in GEOS-4, both 400 underestimating the optical depth due to high clouds in the tropics. These suggest that differing 401 cloud fields including cloud vertical distributions cannot explain the majority of the

402 403 404 405 406 407 408 409 410

\section{Sensitivity to the Magnitude of Cloud Optical Depths}

Comparing the effects of clouds in GEOS1-STRAT and GEOS-3, which feature similar vertical distribution of clouds, provides a sense of the sensitivity of simulated photolysis frequencies and tropospheric oxidants to the magnitude of CODs. To see the full range of sensitivity to COD magnitude, we examine in this section sensitivity simulations where the 
411 magnitude of 3-D CODs is progressively adjusted. We choose GEOS-3 (versus GEOS-4) for

412 these perturbation experiments because its high clouds are optically thicker and probably more

413 realistic (section 3). These results should prove useful for understanding the radiative impact of

414 clouds in other models with similar vertical distributions of clouds. They will also help

415 understand how potential changes in the magnitude of CODs in a future climate may affect

416 tropospheric chemistry. To help understand the results from our sensitivity simulations for

417 different seasons, we first examine the seasonal and latitudinal variability in the distributions of

418 clouds and their effects on photolysis frequencies and tropospheric oxidants.

419 Figure 6 shows the zonal mean latitude-height cross-sections of GEOS-3 monthly mean

420 cloud extinction coefficient $\left(\mathrm{km}^{-1}\right)$ for January, March, June and October. Vertical profiles of 421 monthly zonal mean cloud extinction coefficients at selected latitudes $\left(46^{\circ} \mathrm{N}, 38^{\circ} \mathrm{N}, 30^{\circ} \mathrm{N}\right.$, 422 equator, $30^{\circ} \mathrm{S}, 38^{\circ} \mathrm{S}$, and $\left.46^{\circ} \mathrm{S}\right)$ are shown in Figure $7(0-16 \mathrm{~km})$ and Figure $8(0-3 \mathrm{~km})$, 423 respectively. In all months, GEOS-3 shows high clouds associated with deep convection in the 424 tropics and low-level stratiform clouds at middle and high latitudes. While the overall patterns of 425 cloud distributions are similar in different months, there are significant regional differences. In 426 the tropics, extinction coefficients have a local maximum in the upper troposphere in Jan, March 427 and June; they are more uniform in the upper and middle troposphere in October. In the 428 middle/high latitudes, the $\mathrm{SH}$ exhibits substantially larger extinction in the lower troposphere 429 than the NH does (Figure 8). These relative distributions of clouds will affect how photolysis 430 frequencies and tropospheric oxidants respond to the varying magnitude of CODs.

431 We show in Figure 9 the model calculated percentage changes in monthly zonal mean 432 photolysis frequencies $\mathrm{J}\left(\mathrm{O}^{1} \mathrm{D}\right)$ because of the radiative effects of clouds indicated in Figures 7 433 and 8 . In the tropics, $\mathrm{J}\left(\mathrm{O}^{1} \mathrm{D}\right)$ are enhanced above and reduced below about $7 \mathrm{~km}(5 \mathrm{~km})$ in 
434 January, March and June (October). In January, March and June, the local maximum in cloud 435 extinction coefficients in the upper troposphere prevents solar UV radiation from penetrating 436 down, leading to reductions in $\mathrm{J}\left(\mathrm{O}^{1} \mathrm{D}\right)$ in more of the troposphere; this is particularly true for 437 June. In October, the cloud extinction coefficients in the middle and upper troposphere are more uniformly distributed and the reflection from lower levels becomes more important, resulting in reductions in $\mathrm{J}\left(\mathrm{O}^{1} \mathrm{D}\right)$ in less of the troposphere. In the $\mathrm{SH}, \mathrm{J}\left(\mathrm{O}^{1} \mathrm{D}\right)$ is enhanced in most of the troposphere except near the surface where it is reduced by $\sim 10-30 \%$. In the $\mathrm{NH}$, by contrast, this transition from enhancement to reduction occurs at higher altitudes $(\sim 2-6 \mathrm{~km})$ in all seasons except June, reflecting higher and optically thicker clouds in the NH than in the SH during those seasons (Figure 7). In June, the NH exhibits decreased cloud extinction in the lower free troposphere $(\sim 1-2 \mathrm{~km}$, Figures 6 and 8), allowing more solar radiation reflected back by boundary layer thick clouds. The impact of clouds on $\mathrm{J}\left(\mathrm{NO}_{2}\right)$ (not shown) is similar to that on $\mathrm{J}\left(\mathrm{O}^{1} \mathrm{D}\right)$, but as discussed earlier, $\mathrm{J}\left(\mathrm{NO}_{2}\right)$ is more sensitive to the presence of clouds than $\mathrm{J}\left(\mathrm{O}^{1} \mathrm{D}\right)$. The impact of clouds on $\mathrm{OH}$ concentrations at different latitudes and seasons (not shown) are similar to those on $\mathrm{J}\left(\mathrm{O}^{1} \mathrm{D}\right)$ and $\mathrm{J}\left(\mathrm{NO}_{2}\right)$.

Figure 10 shows the model sensitivities of regional and global mean $\mathrm{OH}$ to the magnitude of CODs in January, March, June and October. $\mathrm{J}\left(\mathrm{O}^{1} \mathrm{D}\right)$ and $\mathrm{J}\left(\mathrm{NO}_{2}\right)$ show similar sensitivities (not shown). Plotted are the percentage changes in global and column (at selected latitudes as indicated in Figures 7-9) mean $\mathrm{OH}$ relative to the standard simulation as the magnitudes of 3-D CODs are adjusted progressively from $-100 \%$ to $100 \%$. A $-50 \%$ change in CODs corresponds to half of the original GEOS-3 CODs with the same 3-D spatial distributions. Global mean $\mathrm{OH}$ (solid line) is shown to have only modest changes at all CODs. Again, this reflects the opposite effects of enhanced (weakened) photochemistry above (below) clouds. It also reflects the overall 
opposite effects of clouds in the $\mathrm{NH}$ and the $\mathrm{SH}$. The slopes of the global mean curve indicate that global mean $\mathrm{OH}$ shows the strongest sensitivity to CODs at the low end. The slopes remain positive and decrease with increasing CODs during January and October; in contrast, the slopes change from positive to negative with increasing CODs during March and June. The decreasing slopes with increasing CODs reflect saturation at large CODs.

In January, March and October, the higher and optically thicker clouds in the NH (Figures 6-8) lead to a decreasing trend in $\mathrm{OH}$ as the CODs increase (Figure 10); the thinner clouds in the SH middle troposphere (Figures 6-8) allow solar radiation to be reflected by the low stratus clouds, resulting in an increasing trend in $\mathrm{OH}$ as the CODs increase (Figure 10). In June, $\mathrm{OH}$ is less sensitive to CODs than in other months ( $\pm 4 \%$ versus $\pm 15 \%)$ in both hemispheres. This reduced sensitivity is because boundary-layer clouds in GEOS-3 become optically thicker and mid-level clouds thinner in the $\mathrm{NH}$ while mid-level clouds become thicker at the SH midlatitudes (Figures 7-8). The latter reflects enhanced frequency of mid-latitude cyclogenesis in the wintertime. Column mean $\mathrm{OH}$ concentrations at all latitudes show higher (lower) sensitivity at small (large) CODs.

We conclude that the modest effects of the perturbation to GEOS-3 CODs on global mean $\mathrm{OH}$ are due to the compensation between above-cloud enhancements and below-cloud reductions (in the vertical) and the opposite responses to this perturbation in the two hemispheres (in the horizontal). The effects would be larger if GEOS-4 cloud distributions were used in these perturbation experiments because of smaller compensations above and below clouds. Monotonic increases in global mean $\mathrm{OH}$ for January and October reflect the dominant backscattering from low-level clouds, while non-monotonic changes for March and June are a result of the sufficiently large optical depths due to high clouds which allow less solar radiation to penetrate 
down to the lower levels and thus limit backscattering from low-level clouds. On the other hand, global and regional column mean $\mathrm{O}_{3}$ essentially increase monotonically when the CODs are varied from $-100 \%$ to $100 \%$, but the effects of clouds remain modest $(<5 \%)$ (not shown).

\section{Sensitivity to Cloud Absorption of Solar Radiation}

We present in this section a cautionary note that 0.99 is too low a value for cloud single scattering albedo (SSA) and is not consistent with current knowledge of cloud absorption of solar radiation at the ultraviolet wavelengths relevant to tropospheric chemistry. This unrealistic value was cited in some recent literature of tropospheric chemistry [e.g., Tie et al., 2003]. Pure water clouds are inefficient absorbers and their SSAs are between 0.999990 and 0.999999 in the ultraviolet wavelength range [Hu and Stamnes, 1993]. Even for contaminated clouds containing black carbon, SSA is still between 0.999 and 0.9999 at 550nm [Chylek et al., 1996]. Using a SSA value as low as 0.99 would lead to large reductions in below-cloud actinic fluxes and thus photolysis frequencies and to a lesser extent above the clouds.

We show in Figure 11 the simulated percentage changes in the June monthly zonal mean $\mathrm{J}\left(\mathrm{O}^{1} \mathrm{D}\right), \mathrm{J}\left(\mathrm{NO}_{2}\right)$ and $\mathrm{OH}$ due to the radiative effects of clouds (GEOS-3), using cloud $\mathrm{SSA}=0.99$ (left panels) and SSA=0.999 (right panels), respectively. These plots can be compared to those presented earlier in this paper (Figure 4 and 5) where SSA=1.0 was used in the standard cloudysky simulation. Using $\mathrm{SSA}=0.99$ is seen to significantly decrease the calculated radiative effects of clouds, both below and above the clouds. We find that while a 1 per mil decrease in SSA (from 1.0 to 0.999 ) leads to only $\sim 1-2 \%$ decrease in $\mathrm{J}\left(\mathrm{O}^{1} \mathrm{D}\right), \mathrm{J}\left(\mathrm{NO}_{2}\right)$ and $\mathrm{OH}$ concentrations, $1 \%$ decrease in SSA (from 1.0 to 0.99 ) would decrease photolysis frequencies and $\mathrm{OH}$ by $\sim 5-10 \%$ in most of the troposphere. This reflects the strong sensitivity of cloud transmittance and cloud 
503 albedo to cloud absorption. Similar calculations with GEOS-4 indicate smaller effects, 504 suggesting in this case the magnitude of CODs is more important than the vertical distribution. In 505 a word, caution should be exercised not to use for cloud SSA a value lower than 0.999 (e.g., 506 0.99) in model simulations of tropospheric chemistry.

\section{Summary and Conclusions}

We have examined the sensitivity of photolysis frequencies and key tropospheric 510 oxidants to cloud vertical distributions and optical properties in terms of the radiative effects of 511 clouds in a global 3-D CTM (GEOS-Chem) coupled with the Fast-J radiative transfer algorithm.

512 The model was driven with a series of meteorological archives (GEOS1-STRAT, GEOS-3 and 513 GEOS-4) generated by the GEOS DAS at the NASA GMAO, which have significantly different 514 cloud optical depths (CODs) and vertical distributions. An approximate random overlap (RAN) 515 scheme was used to take into account the vertical subgrid variability of cloudiness (cloud 516 overlap). The radiative effects of clouds in the model are represented by subtraction of a zero517 CODs simulation from the standard (cloudy-sky) simulation. Our objective was to improve our 518 understanding of the role that different cloud fields played in the variability of tropospheric 519 oxidants among global models in terms of the radiative effects of clouds on tropospheric 520 chemistry.

521 We intercompared the GEOS effective column CODs under the RAN scheme and 522 evaluated them with the satellite retrieval products of radiative mean CODs from the Moderate 523 Resolution Imaging Spectroradiometer (MODIS) and the International Satellite Cloud 524 Climatology Project (ISCCP). All CODs show peaks in the tropics associated with deep 525 convective clouds and at midlatitudes associated with extratropical cyclones in the Northern 
Hemisphere $(\mathrm{NH})$ and marine stratiform clouds in the Southern Hemisphere $(\mathrm{SH})$. However, CODs differ substantially among the GEOS archives. In the tropics, GEOS-4 effective CODs are most close to MODIS and ISCCP radiative mean CODs; at mid-latitudes, GEOS-4 and GEOS-3 effective CODs appear to bracket MODIS and ISCCP radiative mean CODs. With respect to vertical distribution, clouds in GEOS-4 are optically much thinner in the tropical upper troposphere compared to those in GEOS1-STRAT and GEOS-3.

By examining the sensitivity of photolysis frequencies and tropospheric oxidants, with a focus on $\mathrm{J}\left(\mathrm{O}^{1} \mathrm{D}\right), \mathrm{J}\left(\mathrm{NO}_{2}\right), \mathrm{OH}$ and $\mathrm{O}_{3}$, to the three GEOS cloud fields, we illustrated that the radiative impact of clouds on global tropospheric chemistry is more sensitive to cloud vertical distribution than to the magnitude of column COD. Specifically, our model calculations indicate that the changes in global mean $\mathrm{OH}\left(\mathrm{J}\left(\mathrm{O}^{1} \mathrm{D}\right), \mathrm{J}\left(\mathrm{NO}_{2}\right)\right)$ due to the radiative effects of clouds in June are about $0.0 \%(0.4 \%, 0.9 \%), 0.8 \%(1.7 \%, 3.1 \%)$, and $7.3 \%(4.1 \%, 6.0 \%)$, for GEOS1STRAT, GEOS-3 and GEOS-4, respectively. It is important to note that the distribution of photolysis frequencies and $\mathrm{OH}$ concentrations shows much larger changes than global mean values do. For instance, maximum decreases in $\mathrm{OH}$ concentrations of $\sim 15-35 \%$ occur near the midlatitude surface. The effects on global mean OH are similar for GEOS1-STRAT and GEOS-3 due to their similar vertical distributions of clouds, even though the column CODs in the two archives differ by a factor of about 5. Despite a factor of 2 smaller optical depths than those clouds in GEOS-3, clouds in GEOS-4 have a much larger impact on global mean photolysis frequencies and $\mathrm{OH}$. The reason is that with GEOS-4, more solar UV radiation is able to penetrate through the optically thin clouds in the upper troposphere, increasing backscattering from low-level clouds and leading to enhanced photochemical activity through most of the free 
troposphere. The net effects of clouds in the middle troposphere are largely determined by the competition between the radiative effects of high and low clouds.

With each of the three (GEOS1-STRAT, GEOS-3, and GEOS-4) cloud distributions, the model global burden of $\mathrm{O}_{3}$ changes by only a few percent $(<5 \%)$ as a result of radiative perturbations from clouds, consistent with the result of Wild [2007]. In all cases, tropical upper tropospheric $\mathrm{O}_{3}$ is much less sensitive to the radiative effects of clouds than previously reported by Tie et al. [2003] who used the MOZART-2 model ( $\sim 5 \%$ versus $\sim 20-30 \%)$. We argue that differing cloud vertical distributions and optical depths, if present, cannot explain the majority of the discrepancies between the GEOS-Chem and MOZART models.

We performed model perturbation experiments to see the full range of the sensitivities of photolysis frequencies and tropospheric oxidants to CODs with varying magnitudes. The model driven by GEOS-3 predicts only modest changes in global mean $\mathrm{OH}$ concentrations when the magnitudes of 3-D CODs are progressively varied by $-100 \%$ to $100 \%$ without altering cloud spatial distributions. It reflects the compensating effect between above-cloud enhancements and below-cloud reductions as well as the overall opposite responses to the cloud perturbation in the $\mathrm{NH}$ and the SH. The latter was because in most of the year the $\mathrm{NH}$ has clouds that are higher and optically thicker while the SH has thinner (thicker) clouds in the middle (lower) troposphere. Global mean $\mathrm{OH}$ shows the strongest sensitivity at the small end of CODs and becomes more or less saturated at the large end. On the other hand, the effects of clouds on global burden of $\mathrm{O}_{3}$ in these perturbation experiments remain modest $(<5 \%)$.

Caution should be exercised not to use a value for cloud single scattering albedo (SSA) lower than 0.999 in order to be consistent with the current knowledge of cloud absorption at the ultraviolet wavelengths relevant to tropospheric photochemistry. Realistic values for cloud SSA 
are between 0.999 and 1.0. Moreover, the calculated radiative effects of clouds are very sensitive to the specified cloud SSA. Using 0.99 for cloud SSA in our model driven by GEOS-3 would decrease simulated $\mathrm{J}\left(\mathrm{O}^{1} \mathrm{D}\right), \mathrm{J}\left(\mathrm{NO}_{2}\right)$, and $\mathrm{OH}$ concentrations by $\sim 5-10 \%$ in most of the troposphere, relative to $\mathrm{SSA}=1.0$.

Results from our sensitivity studies are robust with respect to varying cloud distributions and optical depths and have important implications for model intercomparisons and for climate feedback on tropospheric photochemistry. First, cloud vertical distributions and optical depths often vary from model to model and may contribute substantially to the model-model discrepancies in tropospheric $\mathrm{OH}$ (oxidation capability). While the differing magnitudes of column CODs may explain part of this discrepancy, the differing vertical distribution of clouds plays a more important role. Thus the impact of errors in the magnitude of CODs on simulated $\mathrm{OH}$ concentrations is smaller than that of errors in the vertical distribution of clouds of similar magnitude. Second, properly representing the vertical distribution of clouds in climate models and its response to climate change is more important for predicting the feedback of cloud changes in a warmer climate on tropospheric photochemistry. This requires an improved representation of clouds, especially their vertical distribution, in current climate models. It is made possible by the launchings of CloudSat and CALIPSO satellites (April 2006) where a unique dataset of not only cloud optical and physical properties but also their vertical distributions will be available for evaluating and constraining the models.

Acknowledgments. This work was supported by NASA Langley Research Center. Thanks are due to Jennifer Logan (Harvard University) for discussions that inspired part of this work, Bernhard Mayer (Institute of Atmospheric Physics of DLR, Germany) for discussions regarding 
594 the cloud single scattering albedo, Yan Feng (University of California at San Diego) for 595 communications about the effect of cloud overlap on photolysis frequencies, and Mat Evans 596 (University of Leeds, UK) for his comments on an earlier manuscript. MODIS and ISCCP 597 products are distributed by NASA Goddard Level 1 and Atmosphere Archive and Distribution 598 System (http://ladsweb.nascom.nasa.gov) and Langley Atmospheric Sciences Data Center, 599 respectively. The GEOS-Chem model is managed by the Atmospheric Chemistry Modeling 600 Group at Harvard University with support from the NASA Atmospheric Chemistry Modeling 601 and Analysis Program (ACMAP). The views, opinions, and findings contained in this report are 602 those of the authors and should not be construed as an official NASA, NOAA or U.S. 603 government position, policy, or decision.

604 


\section{Appendix. Derivation of MODIS and ISCCP all-sky grid-box cloud optical depths}

The albedo $\left(\mathrm{R}_{\mathrm{c}}\right)$ of a non-absorbing, horizontally homogeneous cloud is given by the twostream approximation [Lacis and Hansen, 1974; Seinfeld and Pandis, 1998] as

$$
\mathrm{R}_{\mathrm{c}}=\frac{\sqrt{3}(1-g) \tau_{c}}{2+\sqrt{3}(1-g) \tau_{c}}
$$

where $\tau_{c}$ is in-cloud optical depth (COD) and $g$ is the asymmetry factor. Assuming the value of $g$ for cloud drops of radius much greater than the wavelength of visible light is 0.85 , the above equation becomes

$$
\mathrm{R}_{\mathrm{c}}=\frac{\tau_{c}}{\tau_{c}+7.7}
$$

Therefore, with the average cloud albedo preserved, MODIS or ISCCP grid-box mean cloud albedo $\left(\mathrm{R}_{\mathrm{c}}^{\prime}\right)$ can be expressed as

$$
\mathrm{R}_{c}{ }^{\prime}=\frac{\tau_{c}{ }^{\prime}}{\tau_{c}{ }^{\prime}+7.7}=f \cdot \frac{\tau_{c}}{\tau_{c}+7.7}
$$

where $\tau_{\mathrm{c}}$ ' is all-sky grid-box radiative mean COD and $f$ grid-box cloud fraction. Solving (4) for $\tau_{\mathrm{c}}$, we have

$$
\tau_{c}{ }^{\prime}=\frac{f \tau_{c} \cdot 7.7}{(1-f) \tau_{c}+7.7},
$$

where the unprimed $\tau_{c}$ is the in-cloud radiative mean COD (the proxy geometric mean COD in the case of MODIS) for the region and period under consideration. 


\section{References}

Bey I., D. J. Jacob, R. M. Yantosca, J. A. Logan, B. Field, A. M. Fiore, Q. Li, H. Liu, L. J. Mickley, and M. Schultz (2001), Global modeling of tropospheric chemistry with assimilated meteorology: Model description and evaluation, J. Geophys. Res., 106, 23,073-23,096.

Bloom, S., A. da Silva, D. Dee, M. Bosilovich, J.-D. Chern, S. Pawson, S. Schubert, M. Sienkiewicz, I. Stajner, W.-W. Tan, and M.-L. Wu (2005). Documentation and Validation of the Goddard Earth Observing System (GEOS) Data Assimilation System - Version 4. Technical Report Series on Global Modeling and Data Assimilation (Editor Max J. Suarez), NASA/TM-2005-104606, Vol. 26, NASA Goddard Space Flight Center, Greenbelt, Maryland, April.

Briegleb, B.P. (1992), Delta-Eddington approximation for solar radiation in the NCAR Community Climate Model, J. Geophys. Res., 97, 7603-7612.

Chylek, P., et al. (1996), Black carbon and absorption of solar radiation by clouds, J. Geophys. Res., 101, 23,365-23,371.

Crawford, J.H., D. Davis, G. Chen, R. Shetter, M. Muller, J. Barrick, and J. Olson (1999), An assessment of cloud effects on photolysis rates: Comparison of experimental and theoretical values, J. Geophys. Res., 104, 5725-5734.

Evans, M.J., and D.J. Jacob (2005), Impact of new laboratory studies of $\mathrm{N}_{2} \mathrm{O}_{5}$ hydrolysis on global model budgets of tropospheric nitrogen oxides, ozone, and $\mathrm{OH}$, Geophys. Res. Lett., 32, L09813, doi:10.1029/2005GL022469.

Feng, Y., J.E. Penner, S. Sillman, and X. Liu (2004), Effects of cloud overlap in photochemical models, J. Geophys. Res., 109, D04310, doi:10.1029/2003JD004040. 
Heald, C.L., D.J. Jacob, R.J. Park, B. Alexander, T.D. Fairlie, D.A. Chu, and R.M. Yantosca (2006), Transpacific transport of Asian anthropogenic aerosols and its impact on surface air quality in the United States, J. Geophys. Res., 111, D14310, doi:10.1029/2005JD006847.

Herman, J.R., and E.A. Celarier (1997), Earth surface reflectivity climatology at 340-380 nm from TOMS data, J. Geophys. Res., 102, 28,003-28,011.

Hu, Y.X., and K. Stamnes (1993), An accurate parameterization of the radiative properties of water clouds suitable for use in climate models, J. Climate, 6, 728-742.

Intergovernmental Panel on Climate Change (IPCC) (2001), Climate Change (2001): The Scientific Basis, Cambridge University Press, UK.

Intergovernmental Panel on Climate Change (IPCC) (2007), Climate Change (2007): The Scientific Basis, Cambridge University Press, UK.

Kiehl, J.T., et al. (1998), The National Center for Atmospheric Research Community Climate Model: CCM3, J. Climate, 11, 1131-1150.

Krol, M.C., and M. van Weele (1997), Implications of variations in photodissociation rates for global tropospheric chemistry, Atmos. Environ., 31, 1257-1273.

Lacis, A.A., and J.E. Hansen (1974), A parameterization of the absorption of solar radiation in the Earth's atmosphere, J. Atmos. Sci., 31, 118-133.

Lefer, B.L., R.E. Shetter, S.R. Hall, J.H. Crawford, and J.R. Olson (2003), Impact of clouds and aerosols on photolysis frequencies and photochemistry during TRACE-P: 1. Analysis using radiative transfer and photochemical box models, J. Geophys. Res., 108(D21), 8821, doi:10.1029/2002JD003171.

Liu, H., J.H. Crawford, R.B. Pierce, P. Norris, S.E. Platnick, G. Chen, J.A. Logan, R.M. Yantosca, M.J. Evans, C. Kittaka, Y. Feng, and X. Tie (2006), Radiative effect of clouds on 
tropospheric chemistry in a global three-dimensional chemical transport model, J. Geophys. Res., 111, doi:10.1029/2005JD006403.

Mao, H., W.-C. Wang, X.-Z., Liang, and R.W. Talbot (2003), Global and seasonal variations of $\mathrm{O}_{3}$ and $\mathrm{NO}_{2}$ photodissociation rate coefficients, J. Geophys. Res., 108(D7), 4216, doi:10.1029/2002JD002760.

Martin, R.V., D.J. Jacob, J.A. Logan, I. Bey, R.M. Yantosca, A.C. Staudt, Q. Li, A.M. Fiore, B.N. Duncan, H. Liu, P. Ginoux, and V. Thouret (2002), Interpretation of TOMS observations of tropical tropospheric ozone with a global model and in-situ observations, $J$. Geophys. Res., 107, 4351, doi:10.1029/2001JD001480.

Martin, R.V., C.E. Sioris, K. Chance, T.B. Ryerson, T.H. Bertram, P.J. Wooldridge, R.C. Cohen, J.A. Neuman, A. Swanson, and F.M. Flocke (2006), Evaluation of space-based constraints on global nitrogen oxide emissions with regional aircraft measurements over and downwind of eastern North America, J. Geophys. Res., 111, D15308, doi:10.1029/2005JD006680.

McLinden, C.A., S.C. Olsen, B. Hannegan, O. Wild, M.J. Prather, and J. Sundet (2000), Stratospheric ozone in 3-D models: A simple chemistry and the cross-tropopause flux, $J$. Geophys. Res., 105, 14,653-14,665.

Norris, P. M., and A. M. da Silva (2007), Assimilation of satellite cloud data into the GMAO Finite-Volume Data Assimilation System using a parameter estimation method. Part I: Motivation and algorithm description, J. Atmos. Sci., 64, 3880-3895.

Oreopoulos, L., and R. F. Cahalan (2005), Cloud inhomogeneity from MODIS. J. Climate, 18, $5110-5124$. 
Park R. J., D. J. Jacob, B. D. Field, R. M. Yantosca, M. Chin (2004), Natural and transboundary pollution influences on sulfate-nitrate-ammonium aerosols in the United States: Implications for policy, J. Geophys. Res., 109, D15204, doi:10.1029/2003JD004473.

Platnick, S., M.D. King, S.A. Ackerman, W.P. Menzel, B.A. Baum, J.C. Riedi, and R.A. Frey (2003), The MODIS cloud products: Algorithms and examples from Terra, IEEE Transactions on Geoscience and Remote Sensing, 41(2), 459-473.

Quante, M. (2004), The role of clouds in the climate system, J. Phys. IV France, 121, 61-86.

Rossow, W.B., and R.A. Schiffer (1999), Advances in understanding clouds from ISCCP. Bull. Am. Meteorol. Soc., 80, 2261-2287.

Rossow, W.B., A.W. Walker, D.E. Beuschel, and M.D. Roiter (1996), International Satellite Cloud Climatology Project (ISCCP) documentation of new cloud datasets, Int. Counc. Of Sci. Unions, Paris, January.

Rossow, W.B., C. Delo, and B. Cairns (2002), Implications of the observed mesoscale variations of clouds for the Earth's radiation budget, J. Climate, 15, 557-585.

Seinfeld, J.H., and S.N. Pandis (1998), Atmospheric Chemistry and Physics: From Air Pollution to Climate Change, 1173-1174, pp.1326, John Wiley \& Sons, Inc., New York.

Slingo, J.M. (1987), The development and verification of a cloud prediction scheme for the ECMWF model, Quart. J. Roy. Meteor. Soc., 113, 899-927.

Stephens, G.L. (2005), Cloud feedbacks in the climate system: A critical review, J. Climate, 18, $237-273$.

Takacs, L.L., A. Molod, and T. Wang (1994), Documentation of the Goddard Earth Observing System (GEOS) general circulation model - version 1, NASA Tech. Memo., TM-104606, 1. 
Tang, Y., et al. (2003), Impacts of aerosols and clouds on photolysis frequencies and photochemistry during TRACE-P: 2. Three-dimensional study using a regional chemical transport model, J. Geophys. Res., 108, 8822, doi:10.1029/2002JD003100.

Thompson, A.M. (1984), The effect of clouds on photolysis rates and ozone formation in the unpolluted troposphere, J. Geophy. Res., 89, 1341-1349.

Thompson, A.M., and R.W. Stewart (1991), Effect of chemical kinetics uncertainties on calculated constituents in a tropospheric photochemical model, J. Geophys. Res., 96, 13,08913,108 .

Thompson, A.M. (1992), The oxidizing capacity of the Earth's atmosphere - Probable past and future changes, Science, 256, 1157-1165.

Tie, X., S. Madronich, S. Walters, R. Zhang, P. Rasch, and W. Collins (2003), Effect of clouds on photolysis and oxidants in the troposphere, J. Geophys. Res., 108(D20), 4642, doi:10.1029/2003JD003659.

Wild, O. (2007), Modelling the global tropospheric ozone budget: exploring the variability in current models, Atmos. Chem. Phys., 7, 2643-2660.

Wild, O., X. Zhu, and M.J. Prather (2000), Fast-J: Accurate simulation of in- and below-cloud photolysis in tropospheric chemical models, J. Atmos. Chem., 37, 245-282.

Wu, S., L.J. Mickley, D.J. Jacob, J.A. Logan, R.M. Yantosca, and D. Rind (2007), Why are there large differences between models in global budgets of tropospheric ozone? J. Geophys. Res., 112, D05302, doi:10.1029/2006JD007801.

Yang, H., and H. Levy (2004), Sensitivity of photodissociation rate coefficients and $\mathrm{O}_{3}$ photochemical tendencies to aerosols and clouds, J. Geophys. Res., 109(D24), D24301, doi: 10.1029/2004JD005032. 
Zhang, M.H., et al. (2005), Comparing clouds and their seasonal variations in 10 atmospheric general circulation models with satellite measurements, J. Geophys. Res., 110, D15S02, doi:10.1029/2004JD005021. 
Table 1. Simulated Percentage Changes in the Global Mean Concentrations of Tropospheric Chemical Species, Photolysis Frequencies and Global Mean Lifetimes of Methylchloroform (MCF) and $\mathrm{CH}_{4}$ Due to the Radiative Effects of Clouds with Different Cloud Overlap Assumptions (RAN and LIN) in June and January ${ }^{\mathrm{a}}$, Following Table 4 of Tie et al. [2003] and Table 2 of Liu et al. [2006].

\begin{tabular}{|c|c|c|c|c|c|c|}
\hline \multirow[b]{2}{*}{ Quantity $^{\mathrm{b}}$} & \multicolumn{2}{|c|}{$\begin{array}{c}\text { GEOS1-STRAT } \\
\text { (1996) }\end{array}$} & \multicolumn{2}{|c|}{$\begin{array}{c}\text { GEOS-3 } \\
(2001)\end{array}$} & \multicolumn{2}{|c|}{$\begin{array}{l}\text { GEOS-4 } \\
(2001)\end{array}$} \\
\hline & RAN & LIN & RAN & LIN & RAN & LIN \\
\hline & \multicolumn{6}{|c|}{ June } \\
\hline $\mathrm{OH}$ & 0.00 & -0.73 & 0.80 & 2.05 & 7.26 & 12.63 \\
\hline $\mathrm{O}_{3}{ }^{\mathrm{c}}$ & 1.68 & 3.01 & 3.20 & 5.22 & 0.90 & 1.39 \\
\hline $\mathrm{NO}_{\mathrm{x}}{ }^{\mathrm{d}}$ & 1.65 & 2.88 & 3.95 & 6.35 & 1.35 & 2.29 \\
\hline $\mathrm{HO}_{2}$ & -1.25 & -2.27 & -1.62 & -2.29 & 0.82 & 1.48 \\
\hline $\mathrm{CH}_{2} \mathrm{O}$ & 0.54 & 1.38 & 1.73 & 3.32 & -0.65 & -0.98 \\
\hline $\mathrm{CO}$ & -0.33 & 0.11 & -0.06 & -0.36 & -4.50 & -7.50 \\
\hline $\mathrm{J}\left(\mathrm{O}^{1} \mathrm{D}\right)$ & 0.40 & -0.06 & 1.73 & 3.25 & 4.08 & 7.32 \\
\hline $\mathrm{J}\left(\mathrm{NO}_{2}\right)$ & 0.85 & 0.85 & 3.11 & 5.90 & 5.96 & 10.40 \\
\hline \multirow[t]{2}{*}{$\mathrm{J}\left(\mathrm{CH}_{2} \mathrm{O}\right)$} & 0.72 & 0.70 & 2.70 & 5.18 & 4.93 & 8.73 \\
\hline & \multicolumn{6}{|c|}{ January } \\
\hline $\mathrm{OH}$ & 0.98 & 0.91 & 2.95 & 5.16 & 7.66 & 13.37 \\
\hline $\mathrm{O}_{3}{ }^{\mathrm{c}}$ & 1.45 & 2.61 & 1.91 & 3.39 & 0.87 & 1.37 \\
\hline $\mathrm{NO}_{\mathrm{x}}{ }^{\mathrm{d}}$ & 1.01 & 1.68 & 3.89 & 5.86 & 2.43 & 3.72 \\
\hline $\mathrm{HO}_{2}$ & -0.62 & -1.22 & -0.71 & -1.00 & 0.99 & 1.79 \\
\hline $\mathrm{CH}_{2} \mathrm{O}$ & 0.71 & 1.54 & 1.49 & 2.61 & -0.57 & -1.00 \\
\hline $\mathrm{CO}$ & 0.07 & 0.61 & -0.16 & -0.37 & -3.28 & -5.59 \\
\hline $\mathrm{J}\left(\mathrm{O}^{1} \mathrm{D}\right)$ & 1.43 & 1.62 & 4.00 & 6.58 & 4.89 & 8.59 \\
\hline $\mathrm{J}\left(\mathrm{NO}_{2}\right)$ & 1.81 & 2.32 & 5.72 & 9.43 & 7.14 & 12.06 \\
\hline $\mathrm{J}\left(\mathrm{CH}_{2} \mathrm{O}\right)$ & 1.66 & 2.14 & 5.10 & 8.52 & 6.03 & 10.33 \\
\hline \multirow[t]{2}{*}{$\mathrm{T}(\mathrm{MCF})^{\mathrm{e}}$} & 1.00 & 2.77 & 0.78 & 0.53 & -6.47 & -10.91 \\
\hline & $(6.22)^{f}$ & (6.33) & (6.68) & $(6.66)$ & $(7.36)$ & (7.02) \\
\hline
\end{tabular}




\begin{tabular}{rrrrrrr}
\hline $\mathrm{T}\left(\mathrm{CH}_{4}\right)^{\mathrm{e}}$ & 1.11 & 2.97 & 1.01 & 0.90 & -6.40 & -10.80 \\
& $(10.50)^{\mathrm{f}}$ & $(10.70)$ & $(11.25)$ & $(11.23)$ & $(12.35)$ & $(11.77)$ \\
\hline
\end{tabular}

${ }^{a}$ The radiative effects of clouds is represented by subtraction of the clear-sky (zero cloud optical depths) simulation from the cloudy-sky simulation.

${ }^{\mathrm{b}}$ Global mean concentrations are calculated by dividing the global total moles of a species by those of air. Global mean photolysis frequencies are volume-weighted values. Thermal tropopause is locally diagnosed using the World Meteorological Organization (WMO) definition of tropopause.

cActually the extended odd oxygen family defined as $\mathrm{O}_{\mathrm{x}}=\mathrm{O}_{3}+\mathrm{NO}_{2}+2 \times \mathrm{NO}_{3}+$ peroxyacylnitrates $+\mathrm{HNO}_{4}+3 \times \mathrm{N}_{2} \mathrm{O}_{5}+\mathrm{HNO}_{3}$.

${ }^{\mathrm{d}} \mathrm{NO}_{\mathrm{x}} \equiv \mathrm{NO}+\mathrm{NO}_{2}$

${ }^{e}$ Percentage changes in global annual mean lifetimes of $\mathrm{MCF}$ and $\mathrm{CH}_{4}$. The lifetimes are derived as the ratio of the total burden of atmospheric $\mathrm{MCF}$ or $\mathrm{CH}_{4}$ to the tropospheric loss rate against oxidation by $\mathrm{OH}$.

${ }^{\mathrm{f}}$ Values in the parentheses indicate global annual mean lifetimes (years) of $\mathrm{MCF}$ and $\mathrm{CH}_{4}$ under cloudy conditions. 


\section{Figure Captions}

Figure 1. (a). GEOS1-STRAT (1996), GEOS-3 (2001) and GEOS-4 (2001) monthly zonal mean effective column cloud optical depths as a function of latitude are compared to MODIS (MOD08_M3.005, level-3 monthly global product at $1^{\circ} \times 1^{\circ}$ resolution) and ISCCP (D2, $280 \mathrm{~km}$ equal-area grid) retrievals (all-sky radiative mean) for June 2001. The Approximate Random Overlap (RAN, equation 1) is used to calculate GEOS effective column cloud optical depths. (b). June 2001 GEOS zonal mean total cloud fractions as a function of latitude, compared to ISCCP retrievals (thin black line) and MODIS retrievals (thick black lines - the dashed line is the MOD35 diurnal-average cloud mask and the solid line is the MOD06 COD-retrieval cloud fraction). Zonal means are calculated for MODIS and ISCCP data if there are less than 10\% missing values over the longitudes. See text for details.

Figure 2. Latitude-height cross-sections of monthly zonal mean cloud extinction coefficient (left panels) and cloud fraction (right panels) for June in GEOS1-STRAT (1996), GEOS-3 (2001), and GEOS-4 (2001), respectively. The Approximate Random Overlap (RAN) is used to obtain GEOS grid-box effective cloud optical depths (equation 1). See text for details.

Figure 3. The global distributions of GEOS1-STRAT (1996), GEOS-3 (2001), and GEOS-4 (2001) monthly mean column effective cloud optical depths (left panels) are compared to MODIS and ISCCP retrievals (radiative mean) for March 2001. Note the smaller color scale for GEOS1-STRAT. The Approximate Random Overlap (RAN, see equation 1) is used to calculate GEOS column effective cloud optical depths. MODIS and ISCCP all-sky grid-box mean cloud 
optical depths are averages over both cloudy and clear regions with nonlinear weights that preserve the average cloud albedo (equation 5). Also shown are the probability distribution functions (PDF) of global monthly mean cloud optical depths in each dataset (right bottom panel). See text for details.

Figure 4. Percentage changes in monthly zonal mean $\mathrm{J}\left(\mathrm{O}^{1} \mathrm{D}\right)$ in the troposphere due to the radiative effects of clouds in June, as simulated by the GEOS-Chem model driven with GEOS1STRAT (1996), GEOS-3 (2001) and GEOS-4 (2001), respectively. Filled contour levels are -50, $-30,-20,-10,-5,-2,0,2,5,10,20 \%$. Dotted contours indicate negative changes.

Figure 5. Same as Figure 4, but shown for $\mathrm{OH}$ and $\mathrm{O}_{3}$ concentrations. Contour levels are -50,$30,-20,-10,-5,-2,0,2,5,10,20 \%$. Dotted contours indicate negative changes.

Figure 6. Zonal mean latitude-height cross-sections of GEOS-3 monthly mean cloud extinction coefficient $\left(\mathrm{km}^{-1}\right)$ for January, March, June and October 2001.

Figure 7. Same as Figure 6, but shown as vertical profiles of monthly zonal mean cloud extinction coefficients $\left(\mathrm{km}^{-1}\right)$ at selected latitudes $\left(46^{\circ} \mathrm{N}, 38^{\circ} \mathrm{N}, 30^{\circ} \mathrm{N}\right.$, equator, $30^{\circ} \mathrm{S}, 38^{\circ} \mathrm{S}$, and $46^{\circ} \mathrm{S}$ ) for January, March, June and October 2001. Also shown are averages over all latitudes (solid lines). Vertical profiles between the surface and $3 \mathrm{~km}$ where cloud extinction coefficients may exceed $1.0 \mathrm{~km}^{-1}$ are shown in Figure 8.

Figure 8. Same as Figure 7, but for the altitudes of 0-3 km. 
Figure 9. Same as Figure 7, but for percentage changes in monthly zonal mean $J\left(\mathrm{O}^{1} \mathrm{D}\right)$ due to the radiative effects of clouds.

Figure 10. Sensitivities of mean tropospheric $\mathrm{OH}$ concentrations to the magnitude of cloud optical depths in January, March, June and October, as simulated by the GEOS-Chem model driven with GEOS-3 (2001). Plotted in the figure are the percentage changes in global (solid lines) and column (at selected latitudes, dot and dashed lines) mean $\mathrm{OH}$ relative to the standard simulation as the magnitude of 3-D cloud optical depths is adjusted progressively from $-100 \%$ to $100 \%$. A $-50 \%$ change in cloud optical depths corresponds to half of the original GEOS-3 cloud optical depth with the same 3-D spatial distributions.

Figure 11. Simulated percentage changes in the June monthly zonal mean $\mathrm{J}\left(\mathrm{O}^{1} \mathrm{D}\right), \mathrm{J}\left(\mathrm{NO}_{2}\right)$ and $\mathrm{OH}$ due to the radiative effects of clouds (GEOS-3, 2001), using cloud SSA=0.99 (left panels) and $\mathrm{SSA}=0.999$ (right panels), respectively. 

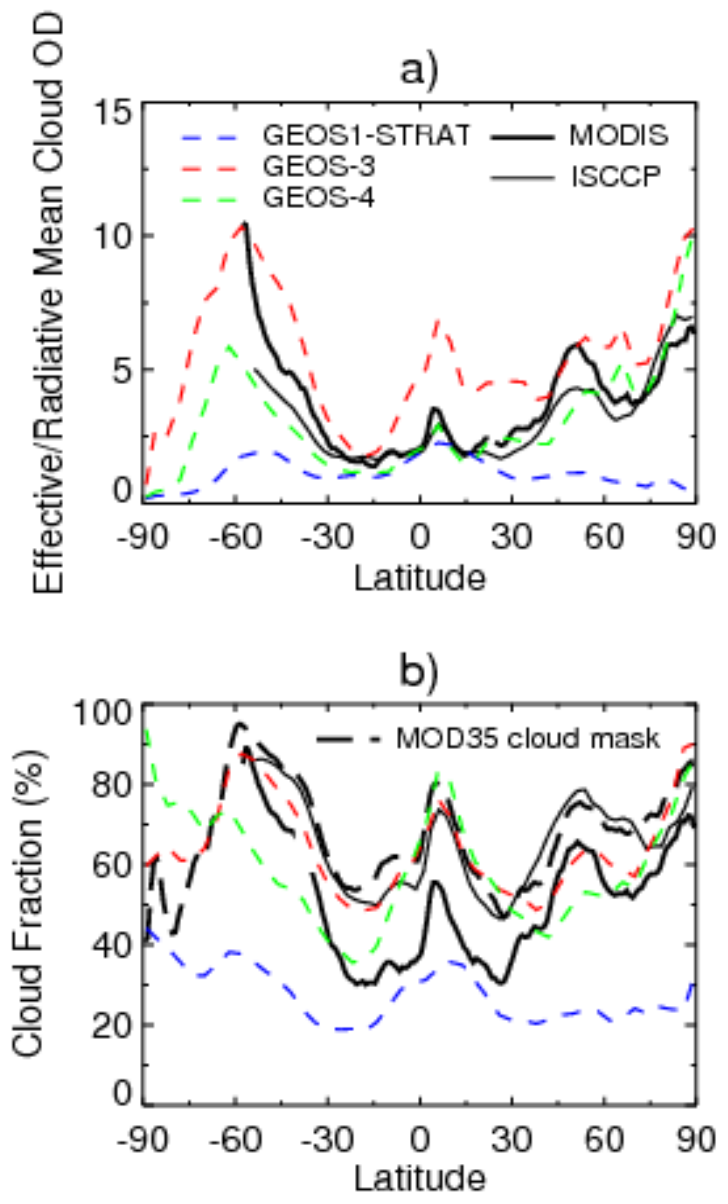

Figure 1. (a). GEOS1-STRAT (1996), GEOS-3 (2001) and GEOS-4 (2001) monthly zonal mean effective column cloud optical depths as a function of latitude are compared to MODIS (MOD08_M3.005, level-3 monthly global product at $1^{\circ} \times 1^{\circ}$ resolution) and ISCCP (D2, $280 \mathrm{~km}$ equal-area grid) retrievals (all-sky radiative mean) for June 2001. The Approximate Random Overlap (RAN, equation 1) is used to calculate GEOS effective column cloud optical depths. (b). June 2001 GEOS zonal mean total cloud fractions as a function of latitude, compared to ISCCP retrievals (thin black line) and MODIS retrievals (thick black lines - the dashed line is the MOD35 diurnal-average cloud mask and the solid line is the MOD06 COD-retrieval cloud fraction). Zonal means are calculated for MODIS and ISCCP data if there are less than 10\% missing values over the longitudes. See text for details. 

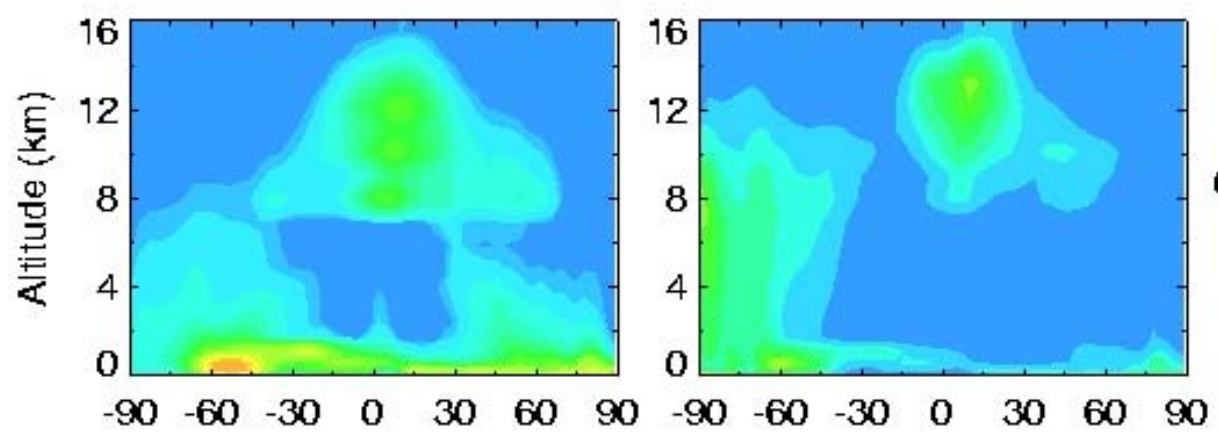

\section{GEOS1-STRAT}

(1996)
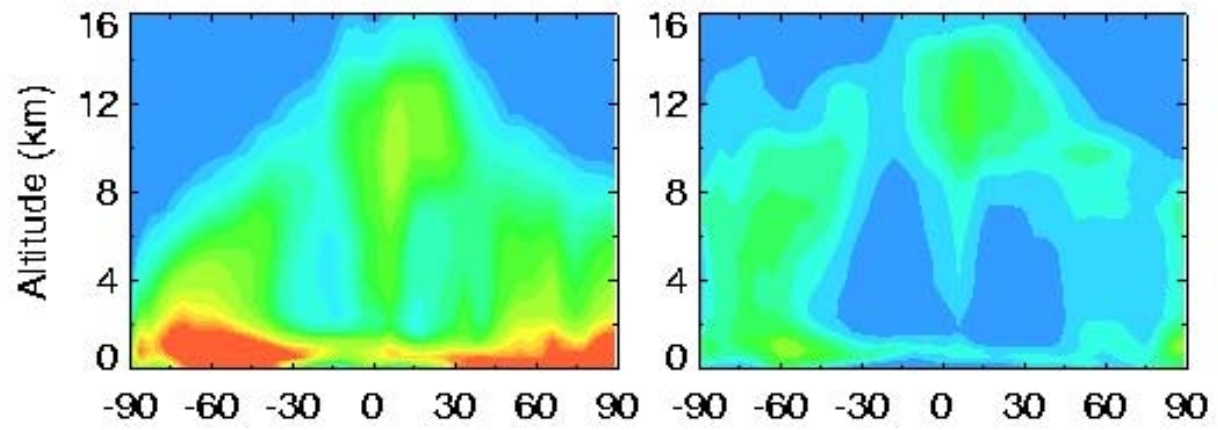

\section{GEOS-3}

(2001)
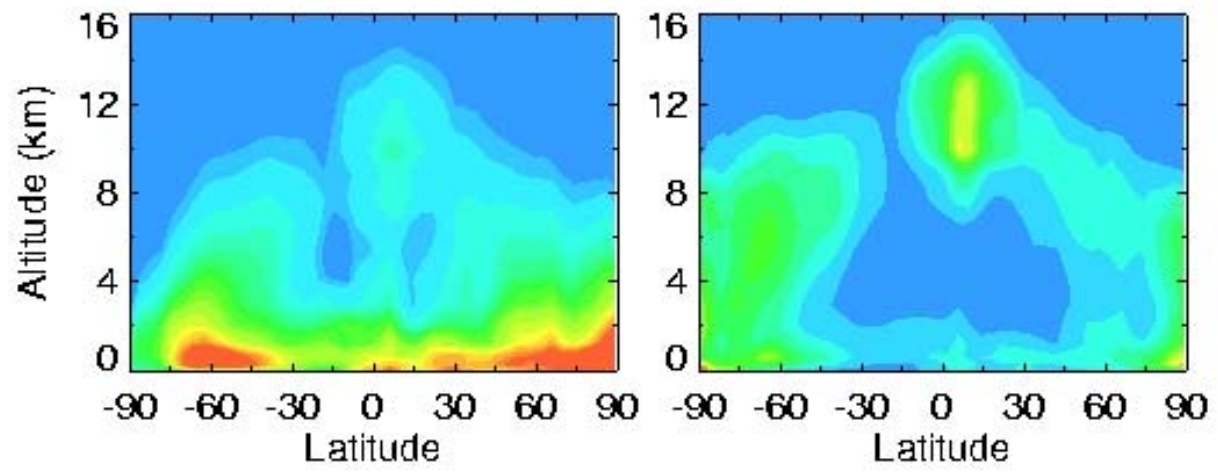

\section{$\frac{\text { GEOS-4 }}{(2001)}$}

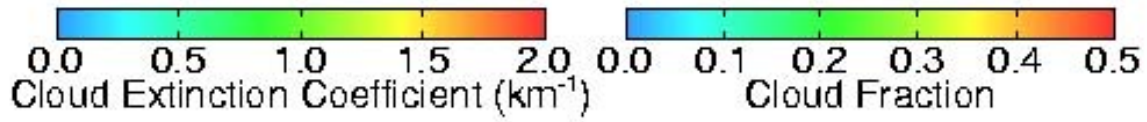

Figure 2. Latitude-height cross-sections of monthly zonal mean cloud extinction coefficient (left panels) and cloud fraction (right panels) for June in GEOS1-STRAT (1996), GEOS-3 (2001), and GEOS-4 (2001), respectively. The Approximate Random Overlap (RAN) is used to obtain GEOS grid-box effective cloud optical depths (equation 1). See text for details. 

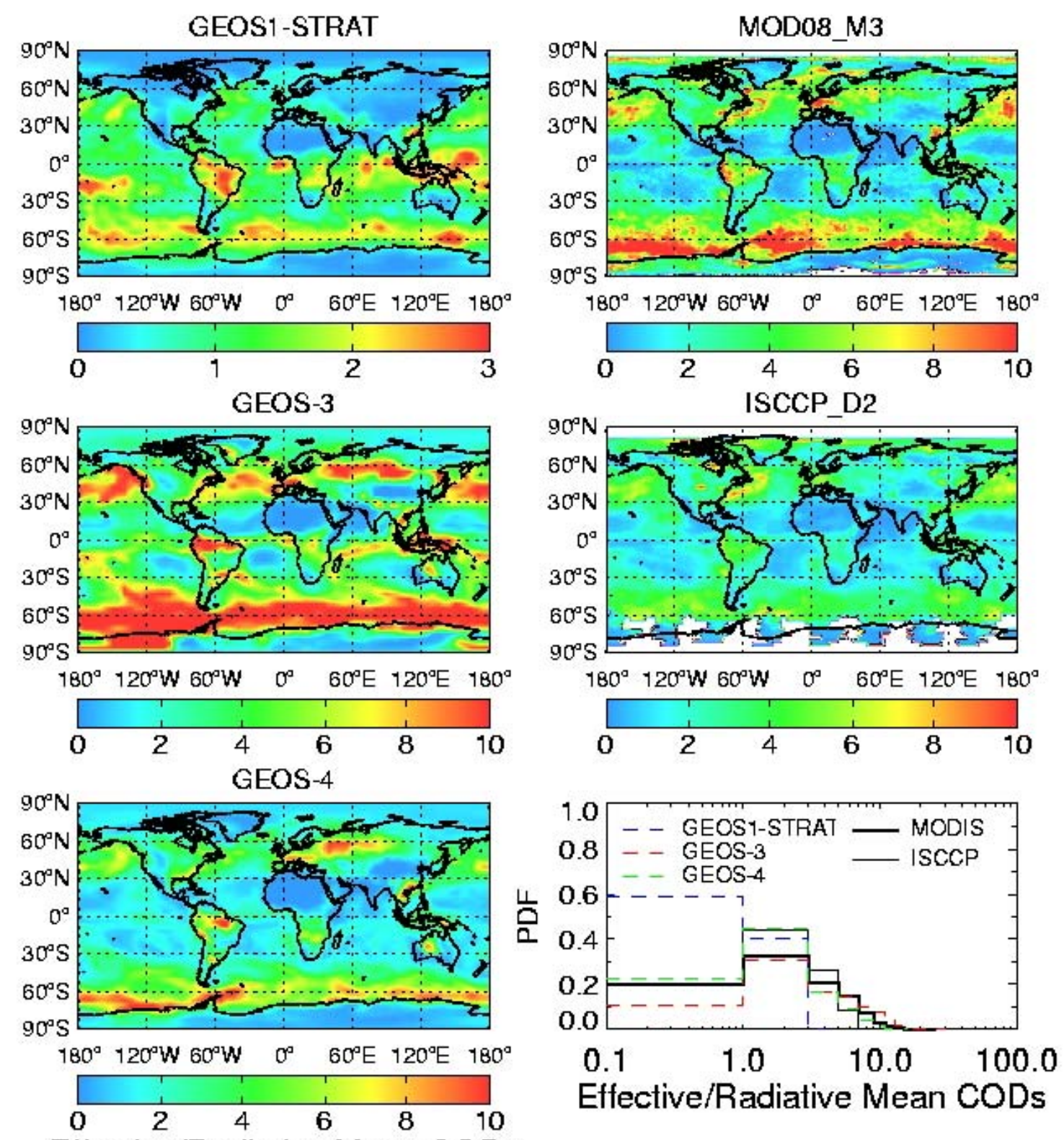

Effective/Radiative Mean CODs

Figure 3. The global distributions of GEOS1-STRAT (1996), GEOS-3 (2001), and GEOS-4 (2001) monthly mean column effective cloud optical depths (left panels) are compared to MODIS and ISCCP retrievals (radiative mean) for March 2001. Note the smaller color scale for GEOS1-STRAT. The Approximate Random Overlap (RAN, see equation 1) is used to calculate GEOS column effective cloud optical depths. MODIS and ISCCP all-sky grid-box mean cloud optical depths are averages over both cloudy and clear regions with nonlinear weights that preserve the average cloud albedo (equation 5). Also shown are the probability distribution functions (PDF) of global monthly mean cloud optical depths in each dataset (right bottom panel). See text for details. 

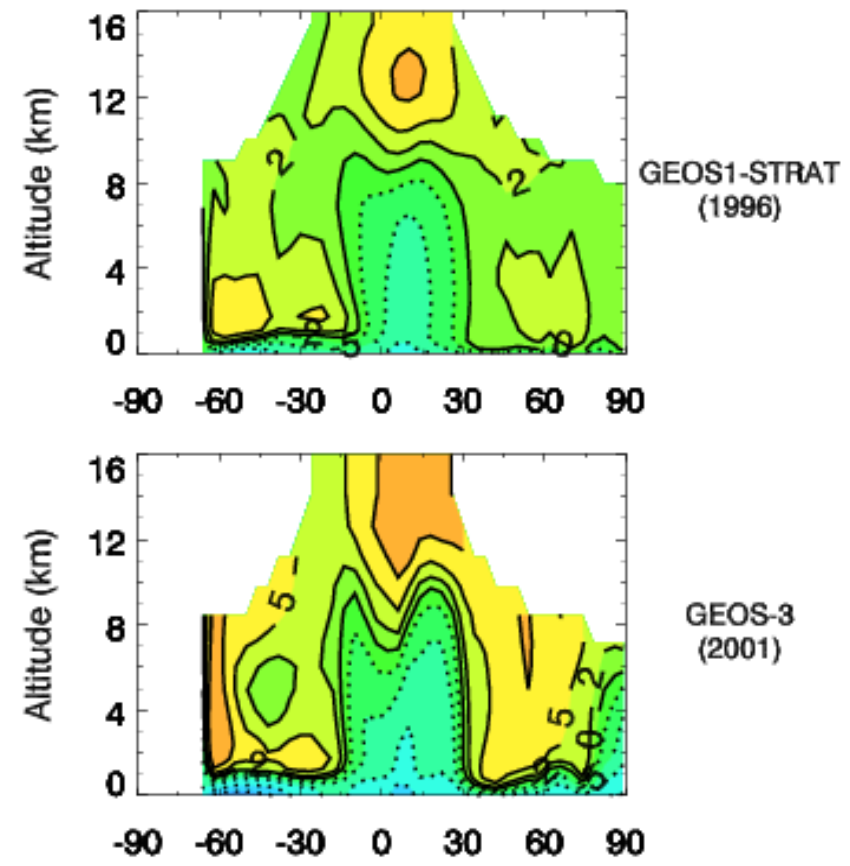

\section{GEOS-3}

(2001)

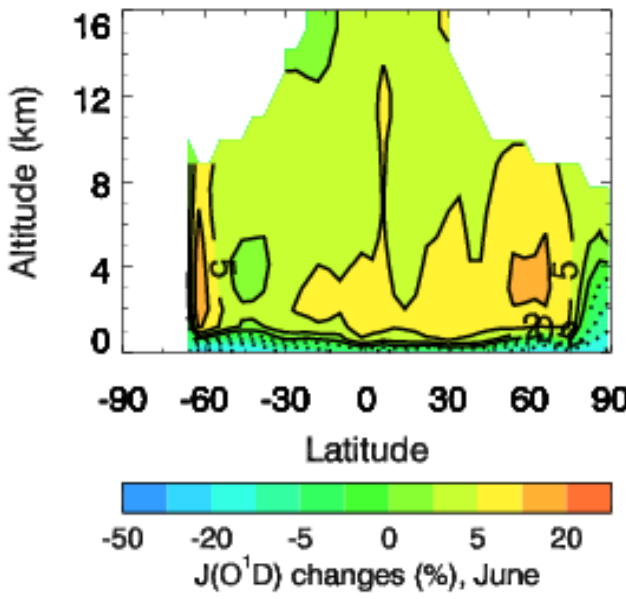

GEOS-4

(2001)

Figure 4. Percentage changes in monthly zonal mean $\mathrm{J}\left(\mathrm{O}^{1} \mathrm{D}\right)$ in the troposphere due to the radiative effects of clouds in June, as simulated by the GEOS-Chem model driven with GEOS1STRAT (1996), GEOS-3 (2001) and GEOS-4 (2001), respectively. Filled contour levels are -50, $-30,-20,-10,-5,-2,0,2,5,10,20 \%$. Dotted contours indicate negative changes. 

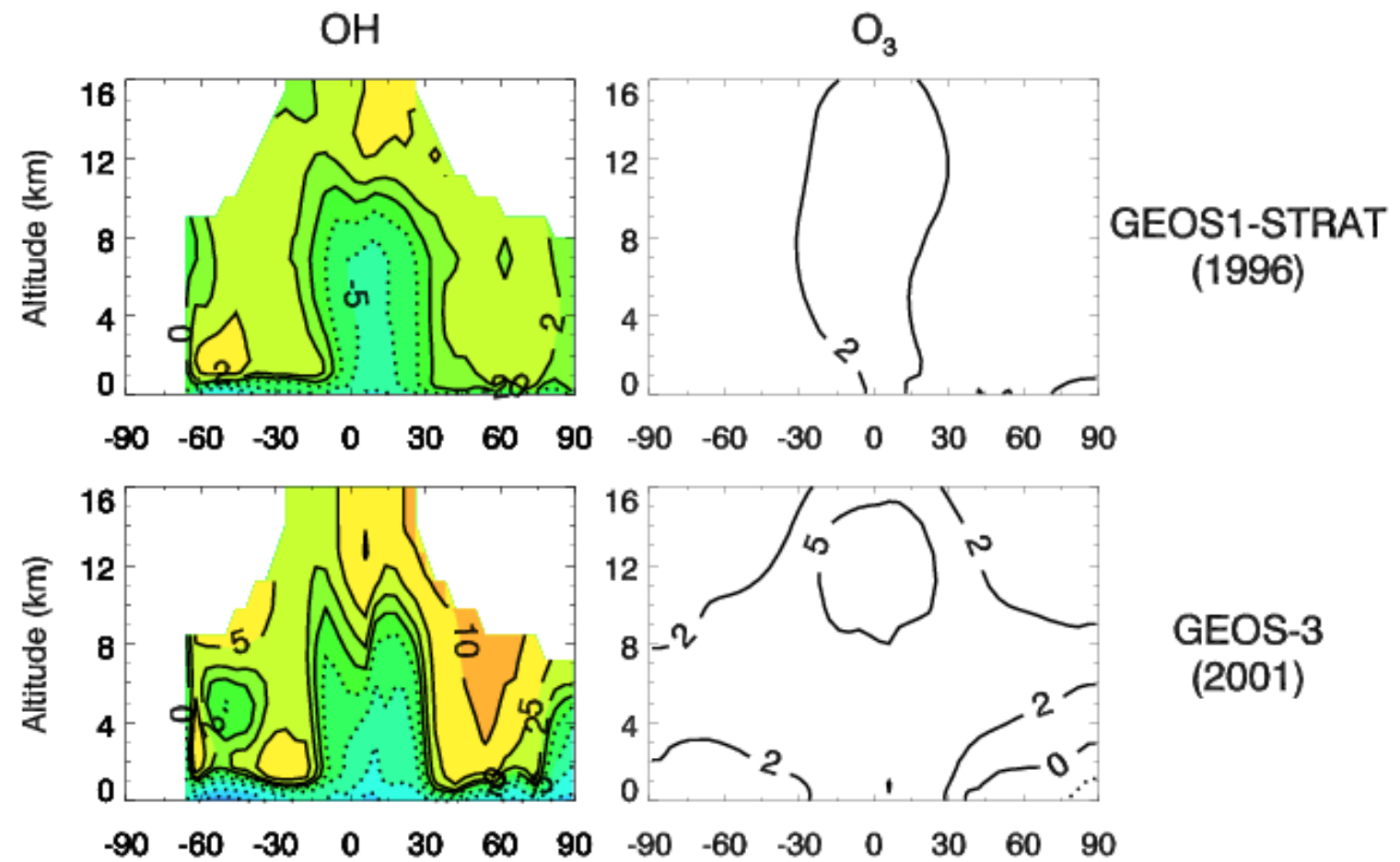

GEOS-3

(2001)
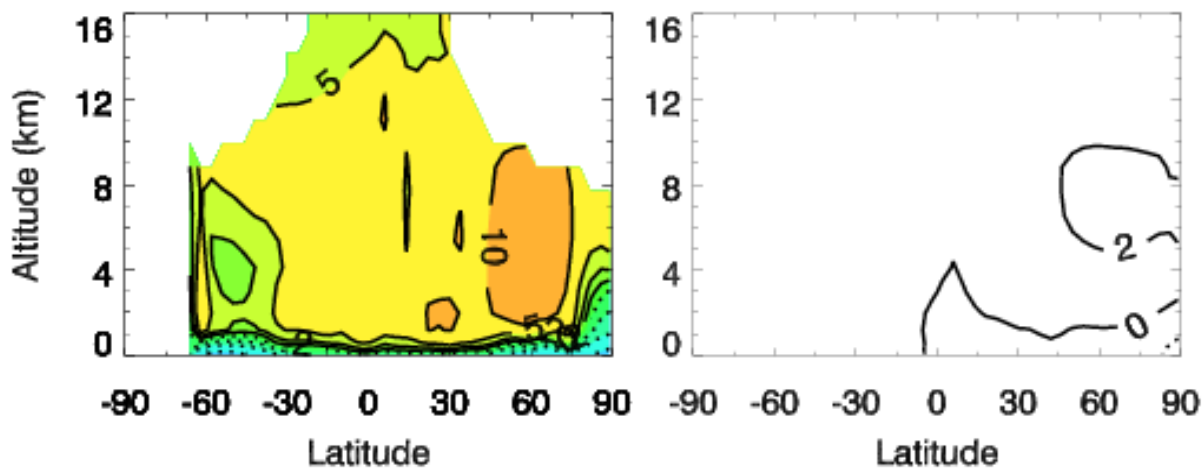

GEOS-4

(2001)

Latitude

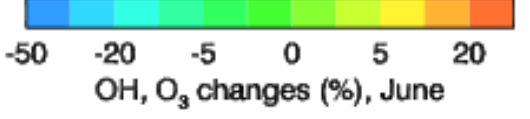

Figure 5. Same as Figure 4, but shown for $\mathrm{OH}$ and $\mathrm{O}_{3}$ concentrations. Contour levels are -50, $30,-20,-10,-5,-2,0,2,5,10,20 \%$. Dotted contours indicate negative changes. 

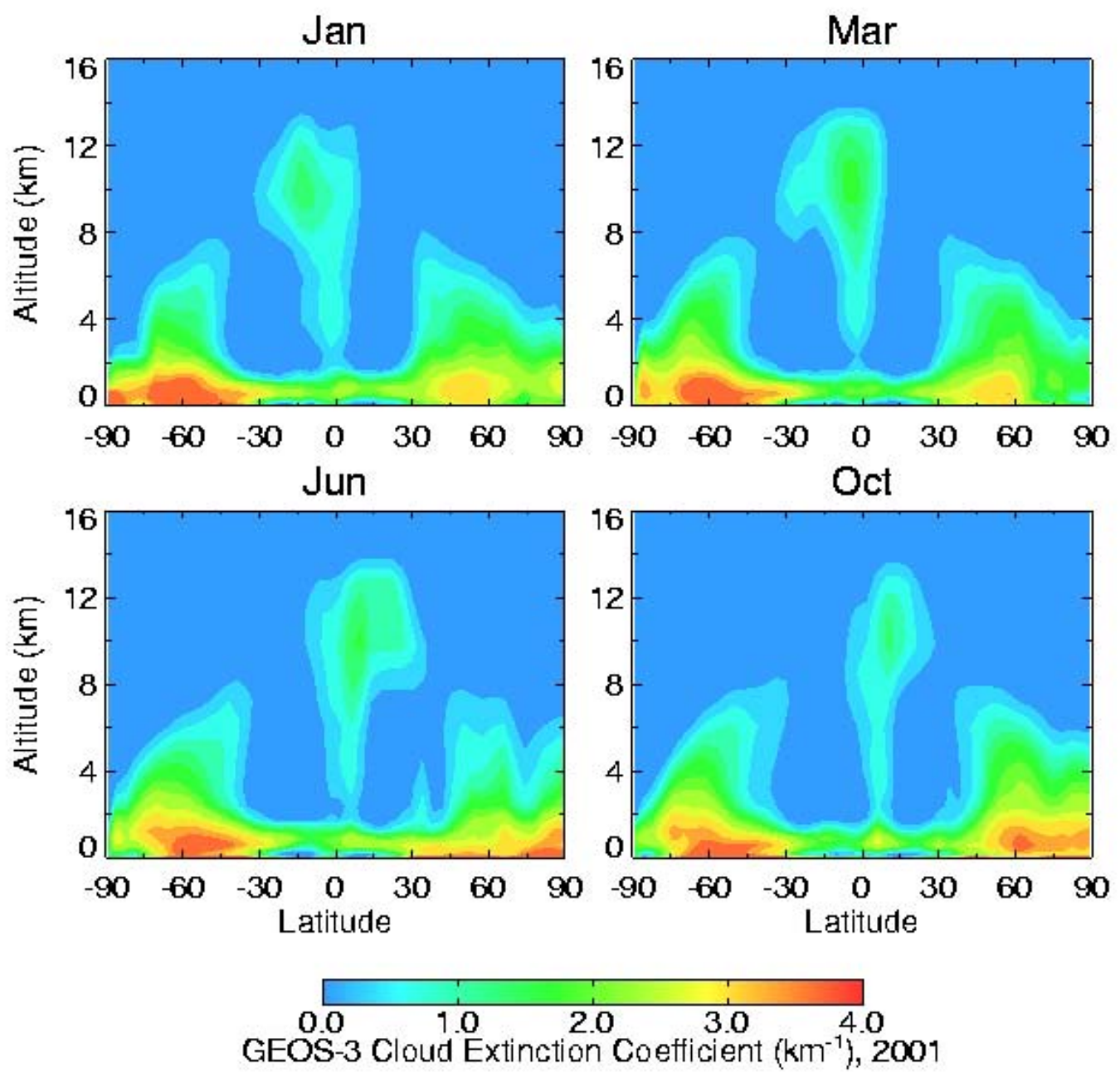

Figure 6. Zonal mean latitude-height cross-sections of GEOS-3 monthly mean cloud extinction coefficient $\left(\mathrm{km}^{-1}\right)$ for January, March, June and October 2001. 
GEOS-3, 2001
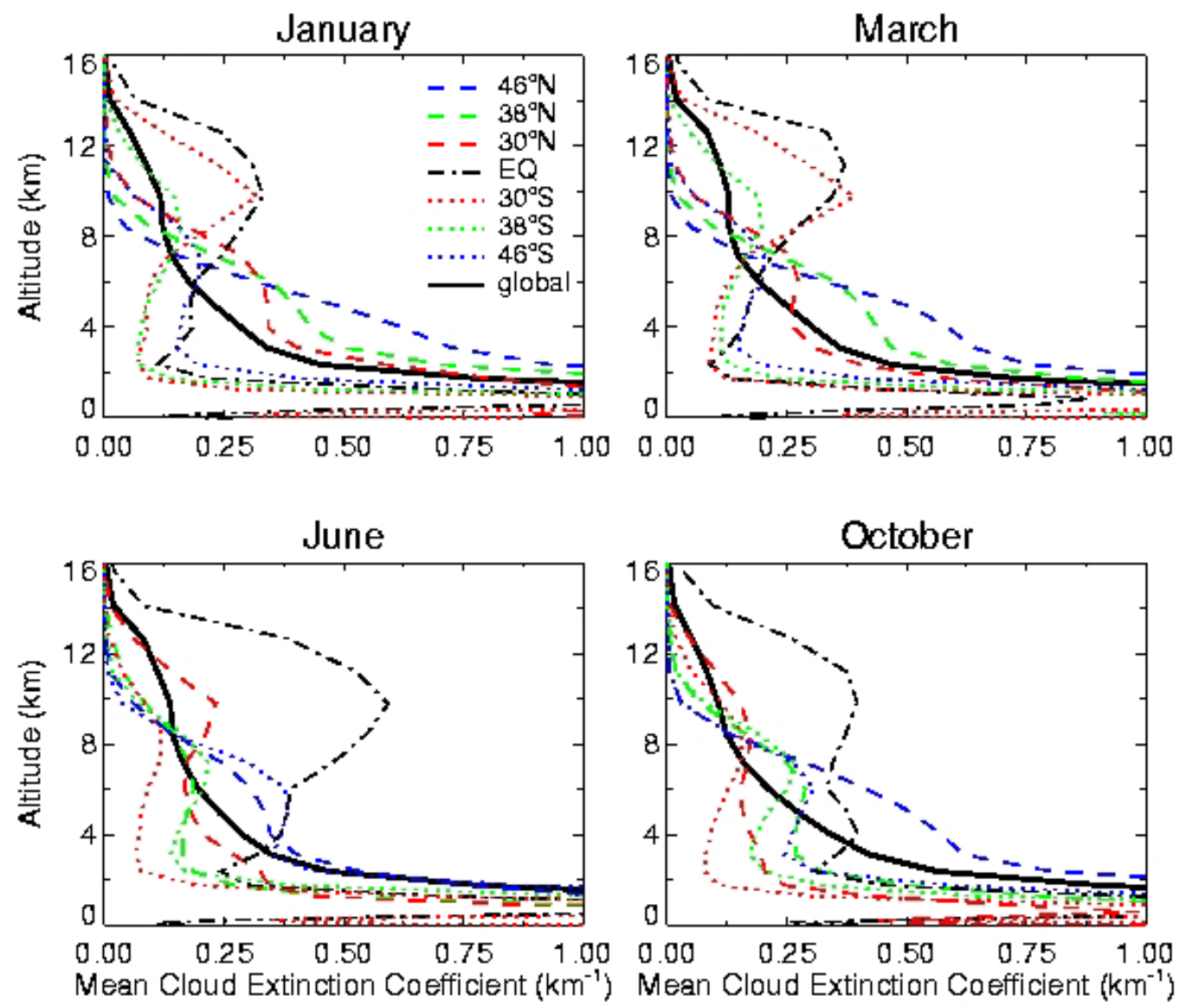

Figure 7. Same as Figure 6, but shown as vertical profiles of monthly zonal mean cloud extinction coefficients $\left(\mathrm{km}^{-1}\right)$ at selected latitudes $\left(46^{\circ} \mathrm{N}, 38^{\circ} \mathrm{N}, 30^{\circ} \mathrm{N}\right.$, equator, $30^{\circ} \mathrm{S}, 38^{\circ} \mathrm{S}$, and $46^{\circ} \mathrm{S}$ ) for January, March, June and October 2001. Also shown are averages over all latitudes (solid lines). Vertical profiles between the surface and $3 \mathrm{~km}$ where cloud extinction coefficients may exceed $1.0 \mathrm{~km}^{-1}$ are shown in Figure 8. 


\section{GEOS-3, 2001}
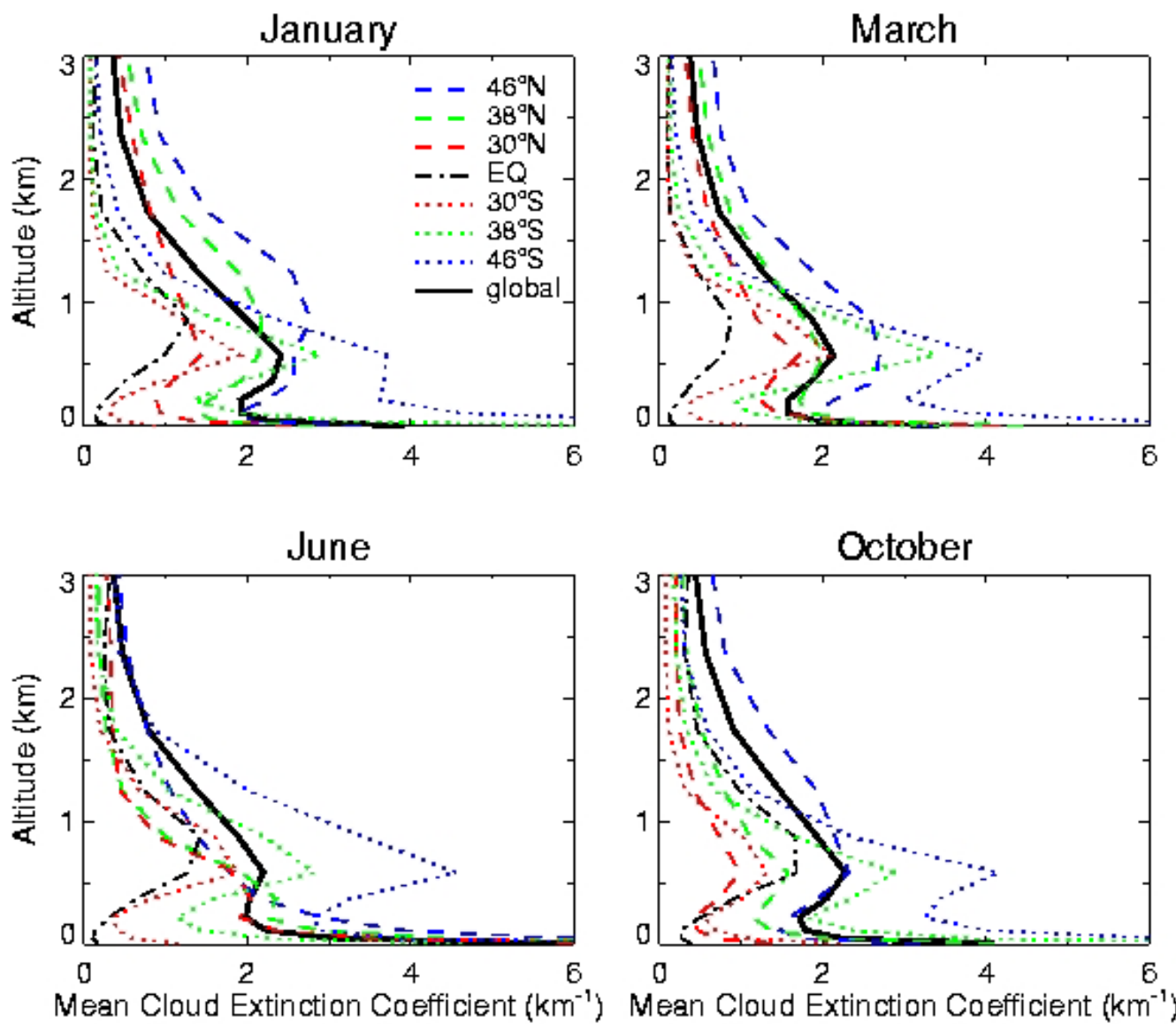

Figure 8. Same as Figure 7, but for the altitudes of $0-3 \mathrm{~km}$. 


\section{GEOS-3, 2001}
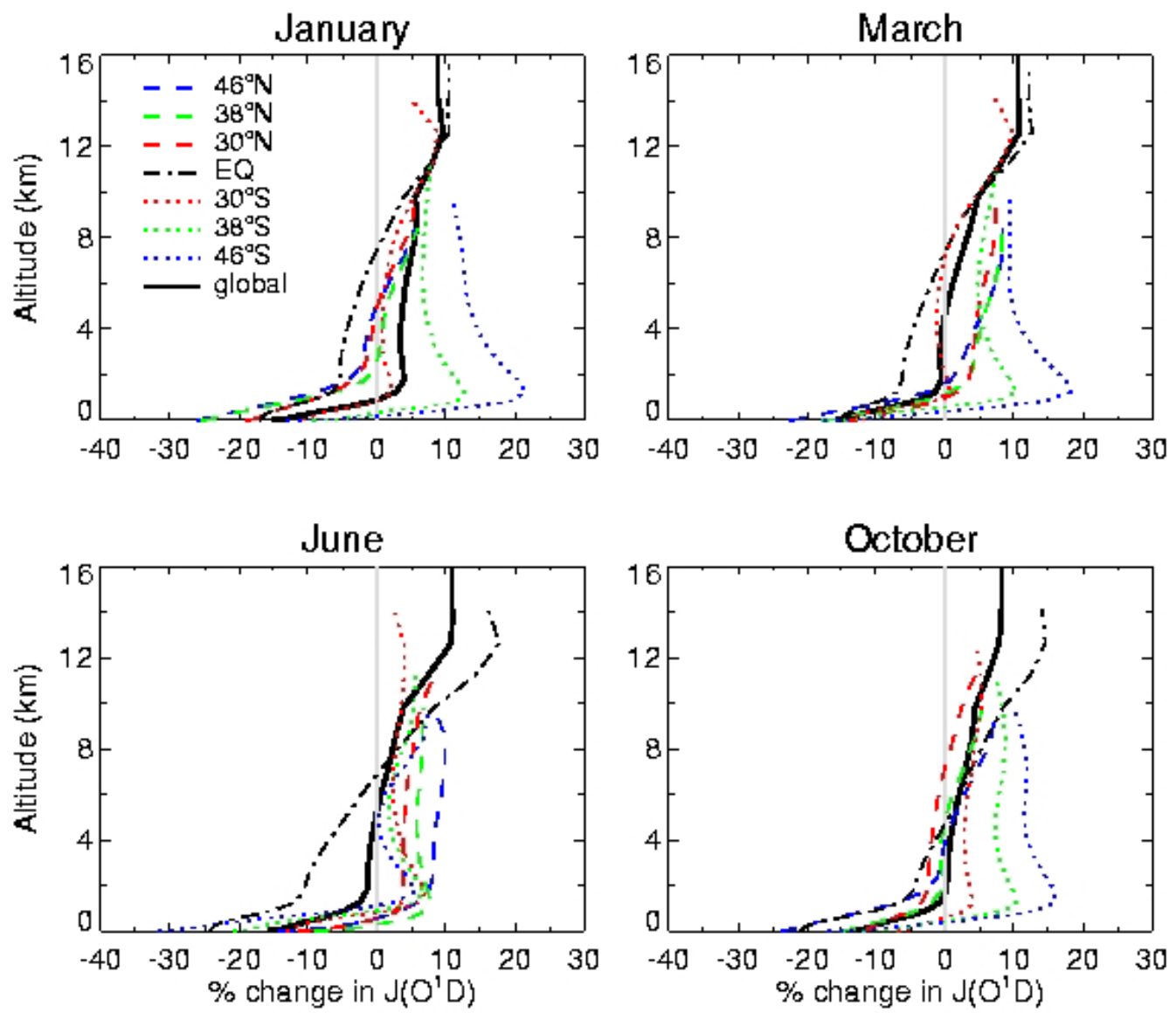

Figure 9. Same as Figure 7, but for percentage changes in monthly zonal mean $J\left(O^{1} D\right)$ due to the radiative effects of clouds. 
RAN, GEOS-3, 2001
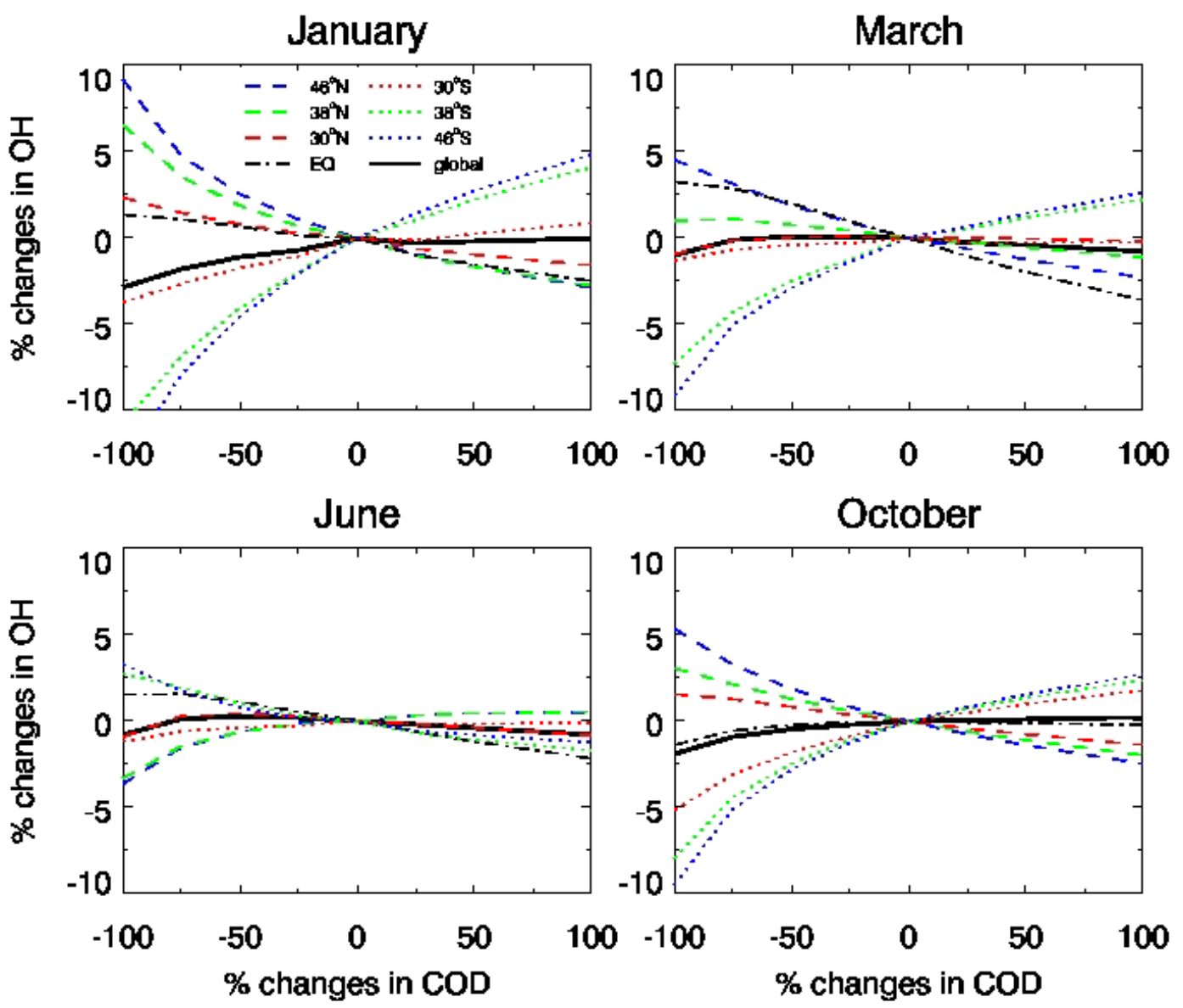

Figure 10. Sensitivities of mean tropospheric $\mathrm{OH}$ concentrations to the magnitude of cloud optical depths in January, March, June and October, as simulated by the GEOS-Chem model driven with GEOS-3 (2001). Plotted in the figure are the percentage changes in global (solid lines) and column (at selected latitudes, dot and dashed lines) mean $\mathrm{OH}$ relative to the standard simulation as the magnitude of 3-D cloud optical depths is adjusted progressively from $-100 \%$ to $100 \%$. A $-50 \%$ change in cloud optical depths corresponds to half of the original GEOS-3 cloud optical depth with the same 3-D spatial distributions. 

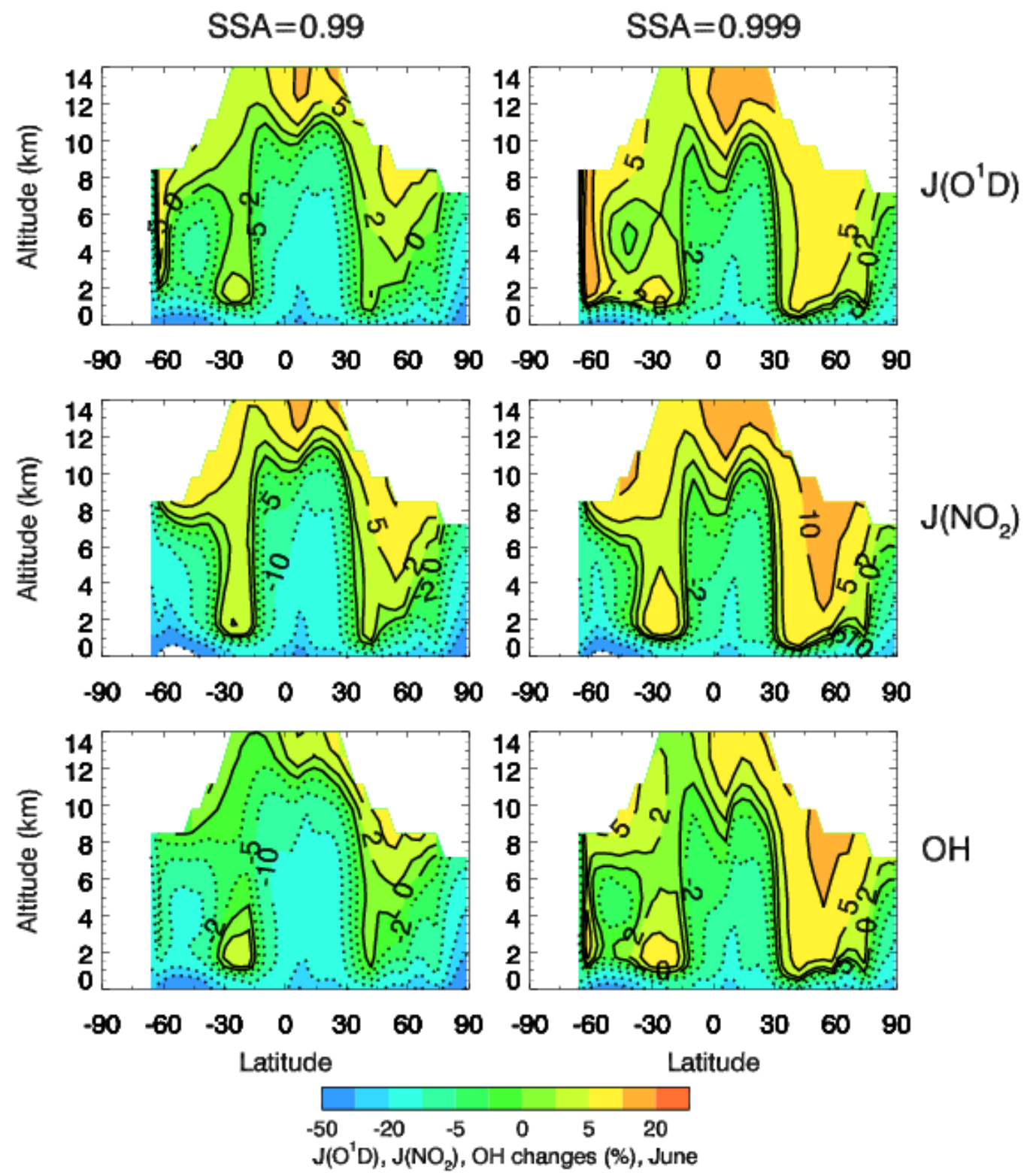

Figure 11. Simulated percentage changes in the June monthly zonal mean $\mathrm{J}\left(\mathrm{O}^{1} \mathrm{D}\right), \mathrm{J}\left(\mathrm{NO}_{2}\right)$ and $\mathrm{OH}$ due to the radiative effects of clouds (GEOS-3, 2001), using cloud SSA=0.99 (left panels) and SSA $=0.999$ (right panels), respectively. 